\title{
FÁCIES SEDIMENTARES E SISTEMAS DEPOSICIONAIS DAS FORMAÇÕES ALTO GARÇAS E VILA MARIA NA REGIÃO DE CHAPADA DOS GUIMARÃES (MT), BORDA NOROESTE DA BACIA DO PARANÁ
}

\author{
MARCIO IVAN CARVALHO MOREIRA \& LEONARDO BORGHI
}

\begin{abstract}
SEDIMENTARY FACIES AND DEPOSITIONAL SYSTEMS OF THE ALTO GARCAS AND VILA MARIA FORMATIONS IN THE CHAPADA DOS GUIMARAES REGION (MT), NORTHWESTERN BORDER OF THE PARANA BASIN The Ordovician-Silurian interval of the Paraná Basin, outcropping in the Chapada dos Guimarães, Campo Verde and Santo Antonio do Leverger counties (MT), is represented by the Alto Garças and Vila Maria formations. This interval is characterized by sixteen lithofacies and two ichnofacies. Among these lithofacies, nine ruditics, six arenitics and one lutitic are identified. The ruditics lithofacies are named massive conglomerate $(\mathrm{Cm})$, conglomerate in tabular beds $(\mathrm{Ct})$, conglomerates and sandstones interbedded in tabular beds $(\mathrm{Ct}(\mathrm{H})$ ), conglomerate with cross-stratification $(\mathrm{Cc})$, massive diamictite (Dmm), massive diamictite with evidence ofressedimentation (Dmm(r)), stratified diamictite (Dms), stratifieddiamictite with evidence of current reworking $(\operatorname{Dms}(\mathrm{c}))$ and stratified diamictite with evidence of ressedimentation $(\mathrm{Dms}(\mathrm{r}))$; the arenitics ones are named massive sandstone (Am), sandstone in tabular beds (At), sandstone with climbing-ripple cross-lamination (Acl), sandstone with cross-stratification (Ac2), sandstone with ripple cross-lamination (Ao) and sandstones and shales interbedded inflaser, wavy and linsen bedding $(\mathrm{Ao}(\mathrm{H}))$; and finally the lutitic lithofacies is named shale with dropstone (Fid). The identified ichnofacies are Skolithos (Sko), by the presence of Skolithos linearis, Arenicolites ichnosp. and Diplocraterion ichnosp., and Cruziana (Crz), by the presence of Arthrophycus alleghaniensis, Palaeophycus tubularis, Aulichnites ichnosp., Lockeia ichnosp., Chondrites ichnosp. and Teichichnus ichnosp. Those facies were related in four depositional systems: Fluvial System (SF-facies Cc), Rudaceous Shallow Marine System (SMRrud-facies Ct, Ct(H), Cm, At, Ac2, Crz), Arenaceous Shallow Marine System (SMRarn-facies Am, At, Ac2, Ao, Ao(H), Sko) and Glaciomarine System (SG-facies Dmm, Dmm(r), Dms, Dms(r), Dms(c), Acl, Fid, Crz). The Alto Garcas Formation, based on the association of the facies At, Am and Sko, is interpreted as the SMRarn system. The Vila Maria Formation is characterized by a succession of (i) beds of the $\mathrm{Cc}$ facies, interpreted as the SF system; (ii) beds of the $\mathrm{Ct}(\mathrm{H})$ facies, interpreted as deposits of a beach-face of the SMRrud system; (iii) beds of the Ct and At facies, interpreted as proximal shoreface deposits dominated by storms of the SMRrud system; (iv) beds of the At, Ct and Crz facies, interpreted as distal shoreface deposits dominated by storms of the SMRrud system; (v) beds of the diamictite facies, and Fid, Crz and Acl facies, all together interpreted as SG system; (vi) beds of the At, $\mathrm{Crz}, \mathrm{Ct}$ and Ac2 facies, interpreted as proximal and distal shoreface deposits dominated by storms of the SMRrud system; (vii) and beds of the At, Sko, $\mathrm{Ao}$ and $\mathrm{Ao}(\mathrm{H})$ facies, interpreted as lagoonal and proximal shoreface deposits dominated by storms of the SMRarn system.

Keywords: sedimentary facies, depositional system, Ordovician, Silurian, Parana Basin, Vila Maria Formation, Alto Garças Formation
\end{abstract}

RESUMO O intervalo Ordoviciano-Siluriano da bacia do Paraná, aflorante na região dos municípios de Chapada dos Guimarães, Campo Verde e Santo António do Leverger (MT), é representado pelas formaç̃es Alto Garcas e Vila Maria. Este intervalo caracteriza-se, simplificadamente, por dezesseis litofácies e duas icnofácies. Dentre as litofácies, são identificadas nove rudíticas, seis areníticas e uma lutítica. As litofácies rudíticas denominadas de conglomerado maciço $(\mathrm{Cm})$, conglomerado em camadas tabulares $(\mathrm{Ct})$, conglomerados e arenitos intercalados em camadas tabulares $(\mathrm{Ct}(\mathrm{H}))$, conglomerado com estratificação cruzada $(\mathrm{Ce})$, diamictito maciço (Dmm), diamicíito maciço ressedimentado $(\mathrm{Dmm}(\mathrm{r}))$, diamictito estratificado $(\mathrm{Dms})$, diamictito estratificado com ação de corrente (Dms(c)) e diamictito estratificado ressedimentado $(\mathrm{Dms}(\mathrm{r}))$; as litofácies areníticas, de arenito maciço (Am), arenito em camadas tabulares (At), arenito com laminação cruzada cavalgante (Ac 1), arenito com estratificação cruzada (Ac2), arenito com laminação cruzada ondulada (Ao) e arenitos e folhelhos intercalados em acamamento flaser, wavy e linsen $(\mathrm{Ao}(\mathrm{H}))$; e a lutítica, de folhelho com clastro caído (Fld). Já as icnofácies identificadas são Skolithos (Sko), pela presença de Skolithos linearis, Arenicolites ichnosp. e Diplocraterion ichnosp., e Cruziana (Crz), pela presença de Arthrophycus alleghaniensis, Palaeophycus tubularis, Aulichnites ichnosp., Lockeia ichnosp., Chondrites ichnosp. e Teichichnus ichnosp. Essas fácies foram relacionadas em 4 sistemas deposicionais: sistema fluvial (SF - fácies Ce), sistema marinho raso rudáceo (SMRrud - fácies $\mathrm{Ct}$, $\mathrm{Ct}(\mathrm{h}), \mathrm{Cm}$, At, $\mathrm{Ac2}, \mathrm{Crz})$, sistema marinho raso arenáceo (SMRarn - fácies Am, At, Ac2, Ao, Ao(H), Sko) e sistema glaciomarinho (SG - fácies Dmm, Dmm(r), Dms, Dms(r), Dms(c), Acl, Fld, Crz). A Formação Alto Garças, com base na associação At, Am e Sko, é interpretada como o SMRarn. A Formação Vila Maria é caracterizada por uma sucessão de (i) camadas da fácies Ce, interpretadas como um depósito fluvioglacial do SF; (ii) camadas da fácies $\mathrm{Ct}(\mathrm{H})$, interpretadas como depósitos de face-de-praia do SMRrud; (iii) camadas das fácies Ct e At, interpretadas como depósitos de antepraia proximal dominado por tempestades do SMRrud; (iv) camadas da fácies At, Ct e Crz, interpretadas como depósitos de antepraia distai dominado por tempestades do SMRrud; (v) fácies de diamictito, fácies Fld, Crz, Acl, interpretadas como SG; (vi) camadas da fácies At, $\mathrm{Crz}, \mathrm{Ct}$, Ac2, interpretadas como depósitos de antepraia proximal e distai dominada por tempestades do SMRrud; (vii) e camadas das fácies At, Sko, Ao, Ao(H), interpretadas como depósitos lagunar e de antepraia proximal dominada por tempestades do SMRarn.

Palavras-chaves: fácies sedimentar, sistema deposicional, Ordoviciano, Siluriano, bacia do Paraná, Formação Vila Maria, Formação Alto Garças.

INTRODUÇÃO A partir de trabalhos de campo desenvolvidos na região dos municípios de Chapada dos Guimarães, Campo Verde e Santo António do Leverger, parte oriental da Chapada dos Guimarães (MT), borda Noroeste da bacia do Paraná, Borghi \& Moreira (1996a) revelaram a ocorrência inédita do intervalo estratigráfico do Paleozóico inferior da bacia, representado pelas formaçōes Alto Garças e Vila Maria (Fig. 1), o qual, desde o mapeamento de Oliveira \& Mühlmann (1967), era erroneamente atribuído à Formação Furnas.

O presente trabalho visa o estudo desse intervalo na região de Chapada dos Guimarães, pela análise das fácies preliminarmente identificadas por Moreira \& Borghi (1997). Nesse artigo, os autores apontaram um conjunto de onze litofácies e duas icnofácies o qual aqui é revisto e analisado. Trabalhos de análise faciológica anteriores desse intervalo já foram realizados por Pereira (1992) para a Formação Vila Maria na borda Nordeste da bacia, o qual apenas identificou um conjunto de onze litofácies, sete das quais correspondem às de Eyles et al. (1983) para depósitos glaciais nessa formação.

UNIDADES LITOESTRATIGRÁFICAS ENVOLVIDAS Grupo Rio Ivaí O Grupo Rio Ivaí foi proposto por Assine et al. (1994) para identificar a sucessão de arenitos da Formação Alto Garças, diamictitos da Formação lapó, e folhelhos e arenitos da Formação Vila Maria, que ocorrem em inconformidade acima do embasamento pré-cambriano da bacia, e estratigraficamente abaixo da Formação Furnas (siluro-devoniano), em contato discordante.

Assine \& Soares (1989) e Assine et al (1994) redefiniram a Formação Vila Maria em sua abrangência estratigráfica, excluindo os diamictitos de sua base que, segundo esses autores, seriam correlacionáveis à Formação lapó de Maack (1947). Essa proposta de emenda à diagnose da Formação Vila Maria não foi seguida neste trabalho, pois parece mais adequado a utilização dos termos estratigráficos "lapó" e "Vila Maria" em suas acepções originais para indicar formações sem correlação física, mesmo que em posição estratigráfica equivalente, resultantes de um mesmo evento deposicional (glaciação ordovício-siluriana) em localidades geografícamente afastadas ( $c f$. Moreira \& Borghi, 1999). Desta forma, evita-se que coexistam dois conceitos estratigráficos acerca da Formação Vila Maria.

Na região de estudo considera-se o Grupo Rio Ivaí composto apenas pelas formações Alto Garças e Vila Maria ( $c f$. Moreira \&Borghi, 1999). Este encontra-se em discordância sobre o embasamento, representado pelos filitos e quartzitos do Grupo Cuiabá (Fig. 1), ou sobre o "arenito Campo Verde" (Borghi \& Moreira 1998b), que ocorrem confinados numa calha de orientação SW-NE na localidade de Torrinhas (ponto 12, Fig. 2). Seu contato de topo com os conglomerados da Formação Furnas é uma discordância angular ( $c f$. Borghi \& Moreira $1996 \mathrm{~b}$ e 1998a).

* Departamento de Geologia, Instituto de Geociências, Universidade Federal do Rio de Janeiro, Av. Brigadeiro Trompowski s/n., CEP 21949-900, Campus Ilha do Fundão, Rio de Janeiro, RJ, Brasil. E-mail: moreira@igeo.ufrj.br 


\begin{tabular}{|c|c|c|c|}
\hline \multicolumn{2}{|c|}{ CRONOESTRATIGRAFIA } & \multirow{2}{*}{\multicolumn{2}{|c|}{ LITOESTRATIGRAFIA }} \\
\hline SISTEMA & SERIEIANDAR & & \\
\hline \multirow{3}{*}{ DEVONIANO } & \multirow{3}{*}{$\begin{array}{l}\text { Famentano } \\
\text { Frannlano } \\
\text { Glvetlano } \\
\text { Erroliano } \\
\text { Emsiano } \\
\text { Praguiano } \\
\text { Lochkoviano }\end{array}$} & \multirow{3}{*}{ 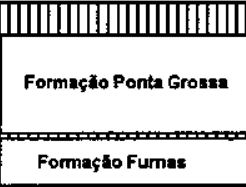 } & 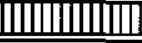 \\
\hline & & & Grupo Parant \\
\hline & & & \\
\hline \multirow[t]{2}{*}{ SILURLAND } & $\begin{array}{l}\text { Pridofl } \\
\text { Ludlow }\end{array}$ & \multirow{3}{*}{ 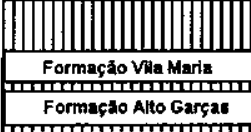 } & \\
\hline & Llandovery & & \multirow[b]{2}{*}{ Grupo Rio Iral } \\
\hline \multirow[b]{2}{*}{ ORDONCIAND } & $\begin{array}{l}\text { Ashgill } \\
\text { Caradoe }\end{array}$ & & \\
\hline & $\begin{array}{l}\text { Llandello } \\
\text { LLanwikn } \\
\text { Arenig } \\
\text { Tremadoc }\end{array}$ & 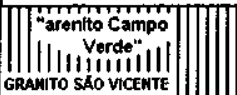 & \\
\hline \multicolumn{2}{|l|}{ CAMBRLANO } & & \\
\hline \multicolumn{2}{|c|}{ PRÉ-CAMBRIANO SUPERIOR } & Embasamento & Grupo Cuistat \\
\hline
\end{tabular}

Figura l - Carta estratigráfica da bacia do Paraná relativa à área de mapeamento (hachuras verticais = hiato elou lacuna estratigráfica) modificado de Borghi \& Moreira (1998a)

FORMAÇÃO ALTO GARÇAS A Formação Alto Garças, formalizada por Assine et al. (1994), foi utilizada para designar a seção predominantemente arenítica que ocorre estratigraficamente acima do embasamento e abaixo da Formação lapó, em contato abrupto diastêmico, no* poços 2-AG-1 -MT (Alto Garças) e 2-RI-1 -PR (Rio Ivai), ambos da PETROBRAS.

$\mathrm{Na}$ área em estudo, a Formação Alto Garças, posicionada no intervalo cronoestratigráfico do limite entre o Caradoc e o Ashgill (Neo-ordoviciano) por Borghi et al. (1997), é composta por conglomerados sobrepostos por arenitos. Posiciona-se em inconformidade sobre o embasamento, representado pelas rochas do Grupo Cuiabá ou sobre o "arenito Campo Verde", e em discordância erosiva sob os conglomerados basais da Formação Vila Maria (sensu Faria 1982), associados a um limite de sequências de tipo 1 (sensu van Wagoner et al. 1988), segundo Borghi \& Moreira (1997). Pode alcançar cerca de $40 \mathrm{~m}$ de espessura na localidade de Torrinhas (ponto 12, Fig. 2) Borghi \& Moreira (1998a).

Em termos paleontológicos, um único icnofóssil foi mencionado na Formação Alto Garças identificado como Skolithos linearis Haldeman 1840. Ocorre em uma densa assembleia comumente designada de piperock, que exemplifica uma icnotrama monoicnoespecífica, comum da icnofácies Skolithos em estratos paleozóicos (Moreira et al. 1997).

FORMAÇÃO VILA MARIA A Formação Vila Maria foi formalizada por Faria (1982) para designar uma sucessão de diamictitos, folhelhos e arenitos que afloram no povoado homónimo, no Estado de Goiás, borda Nordeste da bacia ( $c f$. Moreira \& Borghi 1999). Quanto à idade, segundo Gray et al. (1985) e Grahn (1992), a Formacão Vila Maria é datada do Llandovery (eossiluriano) com base em palinomorfos.

$\mathrm{Na}$ área de estudo, a Formação Vila Maria é composta por uma sucessão de conglomerados, arenitos, diamictitos e folhelhos, conglomerados, e de arenitos, o que levou Moreira \& Borghi (1999) a propor um estratótipo complementar na região. Posiciona-se sobre a Formação Alto Garças em discordância erosiva (limite de sequências de tipo 1) e sob os conglomerados da Formacão Furnas em aparente discordância angular (cf. Borghi \& Moreira 1996a, 1998a). Apresenta espessura média de cerca de $20 \mathrm{~m}$, como observado nas escarpas da fazenda Nossa Senhora de Medianeira (pontos 2 e 3, Fig. 2), nas escarpas próximas à caverna Aroe Jari (ponto 7 , Fig. 2) e na região da fazenda Serrinha (ponto 9, Fig. 2). No morro do Ranchão (ponto 14, Fig. 2), apresenta uma espessura máxima de cerca de $70 \mathrm{~m}$, representando sua sucessão mais contínua nesta região (Borghi \& Moreira 1998a).

Em termos paleontológicos, Borghi et al. (1996) identificaram a icnoespécie Arthrophycus alleghaniensis (Harlan 1831) nas escarpas

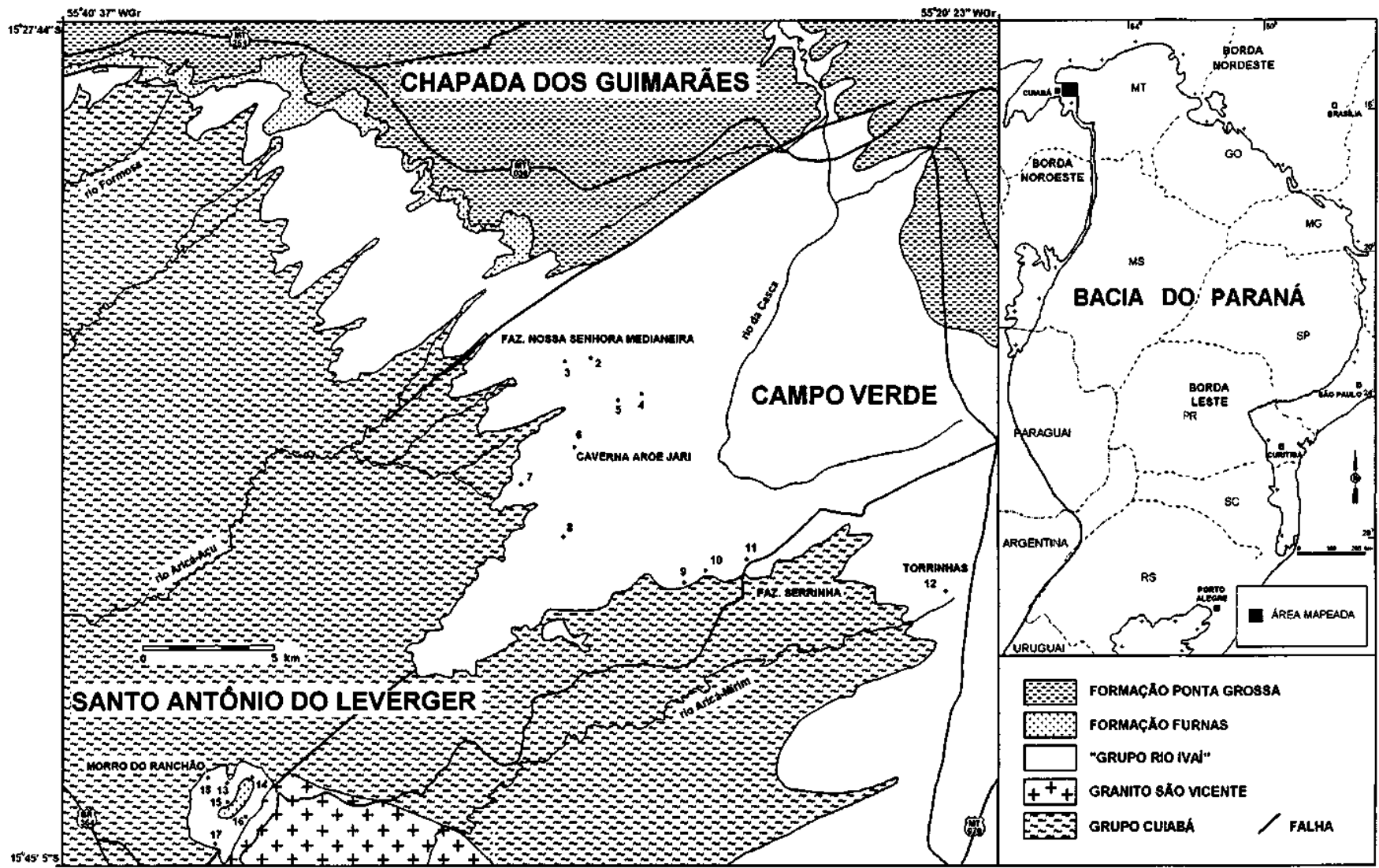

Figura 2 - Mapa geológico da área de estudo com a localização toponímica dos pontos citados no trabalho, (l, fazenda Liberdade, 2 e 3; escarpas da fazenda N.S.de Medianeira; 4 e 5, região da caverna Aroe Jari; 6, caverna Aroe Jari; 7, escarpas da região da caverna Aroe Jari; 8, estrada para Bom Jardim; 9, 10 e 11, escarpas da fazenda Serrinha; 12, Torrinhas; 13, 14, 15, 16, 17 e 18, morro do Ranchão.) - Borghi \& Moreira (1998a) 
próximas a caverna Aroe Jari (ponto 7, Fig. 2). Machado et al. (1997) identificaram o género de biválvio ctenodontídeo Tancrediopsis Beushausen 1895 na região da fazenda Serrinha (ponto 11, Fig. 2) e no morro do Ranchão (ponto 14, Fig. 2); e Mussa et al. (1997) descrevem megafósseis de plantas vasculares primitivas na região da fazenda Serrinha (ponto 11, Fig. 2) atribuíveis à espécie Cooksonia hemisphaerica Edwards 1979 e Cooksonia caledonica Edwards 1970.

FÁCIES SEDIMENTARES O trabalho de descrição dos afloramentos e perfis sedimentográficos das formações Alto Garças e Vila Maria mostrou que estas unidades podem ser caracterizadas através de um conjunto de 18 fácies, composto por 16 litofácies e 2 icnofácies. Dentre as litofácies, foram caracterizadas 9 fácies rudíticas, 5 fácies areníticas e 1 fácies lutítica.

O termo fácies, empregado neste trabalho, refere-se a uma massa de rocha sedimentar que pode ser distinguida das demais por sua geometria, litologia, estruturas sedimentares, paleocorrentes e fósseis (cf. Selley 1985).

No código de litofácies empregado, a primeira letra, maiúscula, representa a litologia, seguida de uma ou duas letras minúsculas representativas da estrutura sedimentar, geometria estratal ou de outro atributo faciológico marcante. Particularmente para a descrição das litofácies de diamictito e de folhelho, foi utilizado o código de fácies de Eyles et al. (1983), enquanto para o estudo das icnofácies foi utilizado o esquema de Frey \& Pemberton (1984).

Litofácies FÁCIES RUDÍTICAS Dentre as fácies rudíticas, separaram-se as suportadas por clastos, aqui designadas apenas de conglomerados, e as suportadas por matriz, designadas de diamictitos.

Nas fácies de conglomerado, excetuando-se aquelas que ocorrem na base da Formação Alto Garças, o arcabouço é constituído predominantemente por seixos de quartzo leitoso e hialino, subanguloso a subarredondado, de até $3 \mathrm{~cm}$ de diâmetro maior, o que permite classificá-los como conglomerados monomíticos. A matriz é constituída por quartzo-arenito mal selecionado, fino a grosso, geralmente de grãos angulosos a subarredondados.

Nas fácies de diamictito, sensu Eyles et al. (1983), predomina a classe areia, aqui considerada como "matriz", de granulometria muito fina a grossa, de composição quartzosa, geralmente mal selecionada (fácies Dmm, Dms, Dms(c) e Dms(r)) ou moderadamente selecionada (fácies Dmm(r)) ou, por vezes, bimodal (Dms e Dms(r)). Excetuando - se a fácies Dmm(r), onde ocorrem muitos clastos de folhelho, os seixos frequentemente são constituídos de quartzo branco leitoso, anguloso a subarredondado, e, mais raramente, seixos euédricos de quartzo hialino e seixos e matacões de filitos e quartzitos. As fácies de diamictito foram observadas exclusivamente na Formação Vila Maria.

Fácies Cm - Conglomerado maciço Compõe-se de um conglomerado médio ou grosso, maciço, moderadamente selecionado e com clastos bem arredondados (Fig. 3). O arcabouco é constituído por seixos de quartzo e quartzito (conglomerado oligomítico) de até $10 \mathrm{~cm}$ de diâmetro. Dispõe-se em conjunto de camadas de espessura muito grande (maior que $1 \mathrm{~m}$ ). Eventualmente, caracteriza-se por uma brecha muito grossa, maciça, mal selecionada, cujo arcabouço é constituído por matacões de quartzito (brecha monomítica) de até $30 \mathrm{~cm}$ de diâmetro. Esta brecha caracteriza aqui uma subfácies $\mathrm{Cm}(\mathrm{B})$; por sua reduzida exposição na área de estudo, fora descrita por Borghi \& Moreira (1996b) no intervalo basal da Formação Alto Garças.

A fácies $\mathrm{Cm}$ é restrita à base da Formação Alto Garças, e é observada na base das escarpas próximas a Torrinhas (ponto 12, Fig. 2). A subfácies $\mathrm{Cm}(\mathrm{B})$ é observada apenas nas escarpas próximas à caverna Aroe Jari (ponto 7, Fig. 2). Esta fácies, semelhante à fácies Gcm de Miall (1996), é produto de fluxos gravitacionais do tipo fluxo-de-detritos pseudoplástico.

Fácies Ct - Conglomerado em camadas tabulares Compõe-se de conglomerados finos ou médios, com boa seleção, sem estrutura aparente. Ocorre em camadas tabulares de espessura pequena e média (ca. 10 a $25 \mathrm{~cm}$ ), muito extensas (decamétrica). $\mathrm{O}$ topo das camadas pode ser nítido plano ou ondulado (megaondulações, Fig. 4), ou gradacional para arenitos. A base destas camadas apresenta-se plana ou irregular. Esta fácies ocorre em conjuntos de camadas tabulares de espessura muito grande, podendo chegar a $6 \mathrm{~m}$. A base da Formação Alto Garças também pode-se caracterizar por um conglomerado médio a grosso, moderadamente selecionado, com clastos bem arredondados, oblatos e orientados no plano horizontal, com arcabouço constituído por se./os de quartzo e quartzito (conglomerado oligomítico) de até $10 \mathrm{~cm}$ de diâmetro.
A fácies Ct é comum no intervalo basal da Formação Vila Maria e pode ser bem observada na entrada sul da caverna Aroe Jari (ponto 6, Fig. 2). Ocorre também no intervalo basal da Formação Alto Garças onde se caracteriza pelos conglomerados médios a grossos, podendo ser bem observada nas escarpas próximas a Torrinhas (ponto 12, Fig. 2).

A persistência horizontal das camadas desta fácies indica deposição por um fluxo uniforme em uma área bastante ampla; ou seja, um fluxo não canalizado, do tipo fluxo turbidítico rudáceo de densidade alta (Lowe 1982), o que permite associá-la à fácies F2 de Mutti (1992). A presença de megaondulações no topo de algumas camadas evidencia o retrabalhamento desses depósitos por fluxos oscilatórios produzidos por tempestades (Leckie \& Walker 1982). Podem ser considerados tempestitos (sensu Ager 1974).

Fácies $C t(H)$ - Conglomerados e arenitos intercalados em camadas tabulares Esta fácies, heterolítica, é composta pela intercalação de camadas tabulares de espessura pequena $(c a .5 \mathrm{~cm})$, predominantemente de conglomerado e, subordinadamente, de arenito (Fig. 5). Os conglomerados são finos ou médios e muito bem selecionados. Os seixos apresentam o eixo maior horizontal, paralelo ao acamamento. $\mathrm{O}$ arenito é médio, quartzoso, bem selecionado, com grãos subarredondados. Ocorrem como um conjunto de camadas tabulares de espessura muito grande $(c a .2 \mathrm{~m})$. Os contatos de topo e de base entre as camadas são sempre planos nítidos.

A fácies $\mathrm{Ct}(\mathrm{H})$, relativamente frequente no intervalo basal da Formação Vila Maria, é bem observada na localidade de Torrinhas (Ponto 12, Fig. 2). Interpreta-se como o produto do retrabalhamento de depósitos macroclásticos grossos por correntes oscilatórias, aqui relacionadas ao espraiamento marinho (swash e backswasti), pela ação de ondas, que causam a segregação das pequenas camadas de conglo-

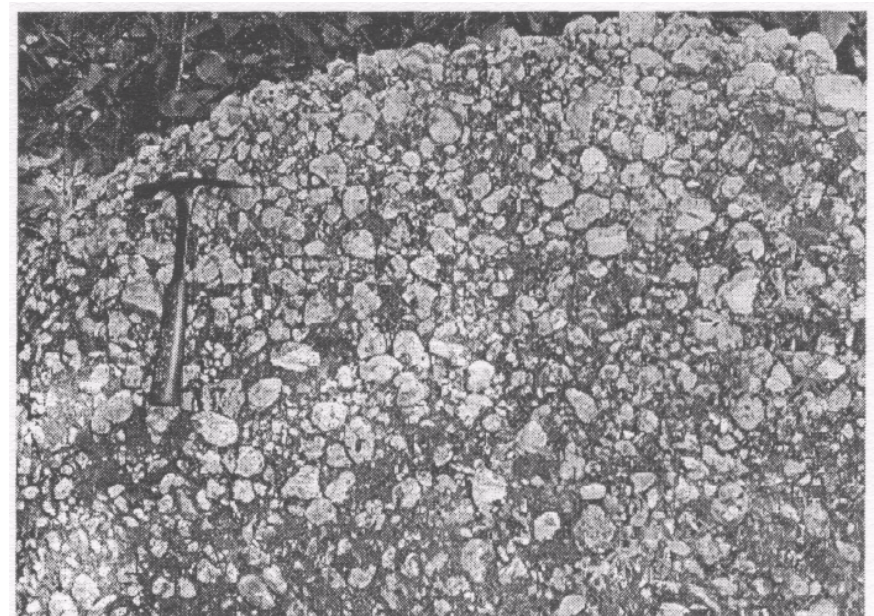

Figura 3 - Fácies Cm. Observar os clastos arredondados. Base da Formação Alto Garças (ponto 12, Fig. 2).

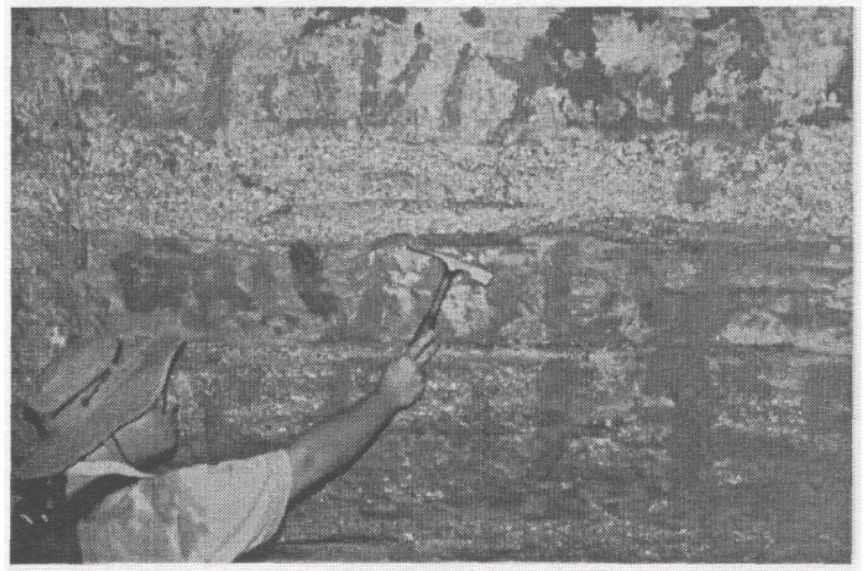

Figura 4 - Fácies Ct. Observar o topo levemente ondulado, tabularídade e extensão. Intervalo basal da Formação Vila Maria (ponto 6, Fig. 2). 
merado/arenito e orientação dos macroclastos (Clifton et al. 1971). Assemelha-se às fácies rudáceas retrabalhadas pelo espraiamento marinho em zonas de face-de-praia descritas por Nemec \& Steel (1984) e por Bourgeois \& Leithold (1984).

Fácies Ce - Conglomerado com estratificação cruzada Compõe-se de conglomerados finos ou médios, com estratificação cruzada e de seleção moderada. Muitos dos clastos maiores do arcabouço estão concentrados ao longo dos estratos cruzados (Fig. 6), o que produz uma distribuição irregular da matriz arenosa. Ocorre em camadas lenticulares isoladas que variam de $40 \mathrm{~cm}$ até cerca de $1,5 \mathrm{~m}$. A base das camadas tem caráter erosivo e o topo apresenta-se plano.

A fácies Ce ocorre na base da Formação Vila Maria e é bem observada na localidade de Torrinhas (ponto 12, Fig. 2).

Associa-se à acreção frontal de megaformas-de-leito não-periódicas, que migram sob condições variáveis de canalização de um fluxo, caracterizado por fortes correntes subaquosas trativas unidirecionais. Segundo Miall (1996), a fácies Gp, com a qual se assemelha, é produzida pela migração de barras durante os estágios de inundação dentro de um canal confinado.

Variações da textura e da estrutura dos cascalhes depositados pelas correntes subaquosas refletem a extrema instabilidade do fluxo e da taxa de transporte das barras de cascalho. Os cascalhes tendem a ser transportados por repetidos pulsos, que refletem os padrões de turbulência e do modo em que esses são transportados a partir da migração das barras (Miall 1996). Isso pode explicar o fato de a fácies Ce não apresentar uma boa seleção, tendo quantidades variáveis de clastos e matriz.

Fácies Dmm - Diamictito maciço $\mathrm{Na}$ área de estudo, esta fácies é composta de um diamictito maciço, de cores cinza, branco e avermelhada (Fig. 7), disposto em conjunto de camadas de espessura muito grande.

Esta fácies foi descrita em todos os pontos onde foram encontrados diamictitos; porém, pode ser melhor observada na região próxima às cavernas (pontos 4 e 5, Fig. 2), na antiga estrada para Bom Jardim (ponto 8, Fig. 2) e na fazenda Liberdade (ponto 1, Fig. 2). Representa possivelmente fluxos gravitacionais subaquosos do tipo fluxos-de-detritos em um contexto glacial ( $c f$. Borghi \& Moreira 1996c), ou por decantação de chuva de detritos ("ram out"), em acordo com a interpretação de Eyles et al. (1993).

Fácies D mm (r) - Diamictito maciço ressedimentado $\mathrm{Na}$ área de estudo, esta fácies é composta de um diamictito macico, de cores branca a acinzentada, com abundantes intraclastos de folhelho angulosos, geralmente deformados, e, menos frequentemente, seixos de quartzo. Dispõe-se em conjunto de camadas de espessura muito grande. Tem contato de base erosivo, evidenciado pelos clastos de folhelho pertencentes a fácies Fld (folhelho com clastro caído, definida adiante), com a qual ocorre associada.

Esta fácies foi observada em uma única localidade próxima à fazenda Serrinha (ponto 10, Fig. 2), e tendo sido reconhecida inicialmente como a fácies Dms(r) (diamictito estratificado ressedimentado, definida adiante) por Borghi \& Moreira (1996c). É interpretada como fluxo-de-detritos subaquosos que retrabalham depósitos previamente acumulados (ressedimentação) em um contexto glacial. Esta fácies de diamictito, segundo Eyles et al. (1993), é típica de fluxos-de-detritos subaquosos resultantes da ressedimentação por escorregamentos de sedimentos de pouca variedade composicional. Aconstatação de sedimentos de uma litologia predominante, no caso intraclastos de folhelho, sugere que provavelmente o fluxo responsável pela deposição desta fácies não tenha viajado por grandes distâncias. Clastos mais raros, como os de quartzo, que também são encontrados nesta fácies, são provavelmente clastos caídos (dropstones) liberados por icebergs (decantação por chuva de detritos).

Fácies Dms - Diamictito estratificado $\mathrm{Na}$ área de estudo, esta fácies é composta de um diamictito estratificado, de cores avermelhadas, dispostos em camadas tabulares e lenticulares de espessura média a grande ( $c a .20$ a $40 \mathrm{~cm}$ ), compondo conjunto de camadas de aproximadamente $5 \mathrm{~m}$ de espessura (Fig. 8).

Pode-se observar esta fácies no caminho para a caverna Aroe Jari (pontos 4 e 5, Fig. 2) e nas escarpas da fazenda Nossa Senhora Medianeira (pontos 2 e 3, Fig. 2). A sua característica marcante é a disposição em camadas tabulares de espessura pequena a média com certa continuidade lateral, que possivelmente relaciona a sua génese com fluxos gravitacionais subaquosos, talvez mistos entre o fluxo-dedetritos e o "fluxo turbidítico arenáceo de densidade alta" de Lowe (1982) em um contexto glacial (Eyles et al. 1985).

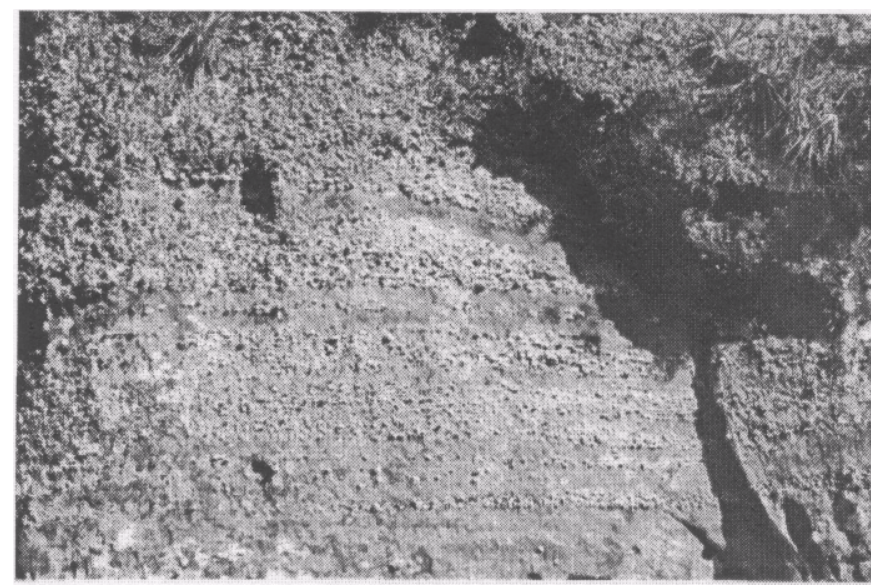

Figura 5 - Fácies Ct(H). Observar a segregação dos clastos, persistência e tabularidade das camadas de conglomerados e arenitos. Intervalo basal da Formação Vila Maria (ponto 12, Fig. 2).

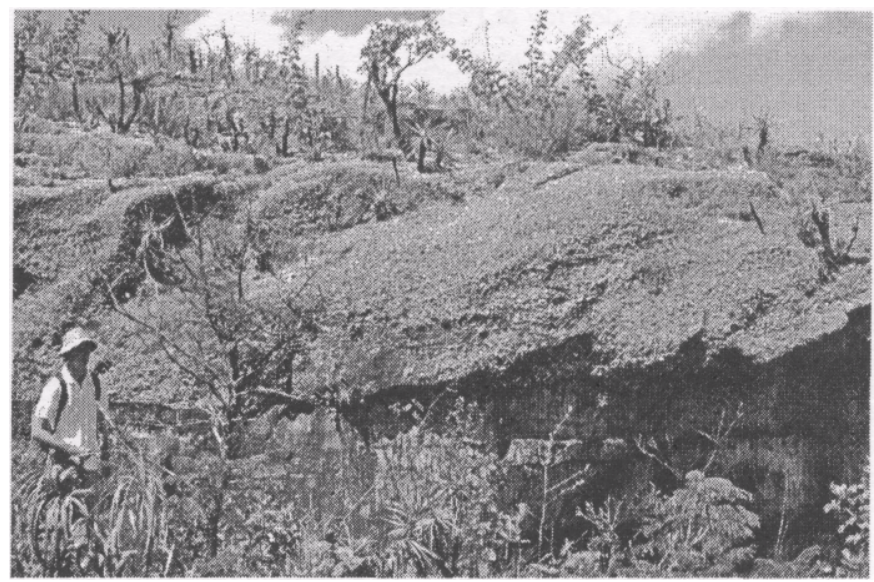

Figura 6 - Fácies Ce. Observar os estratos cruzados e a espessura da camada. Base da Formação Vila Maria (ponto 12, Fig. 2).

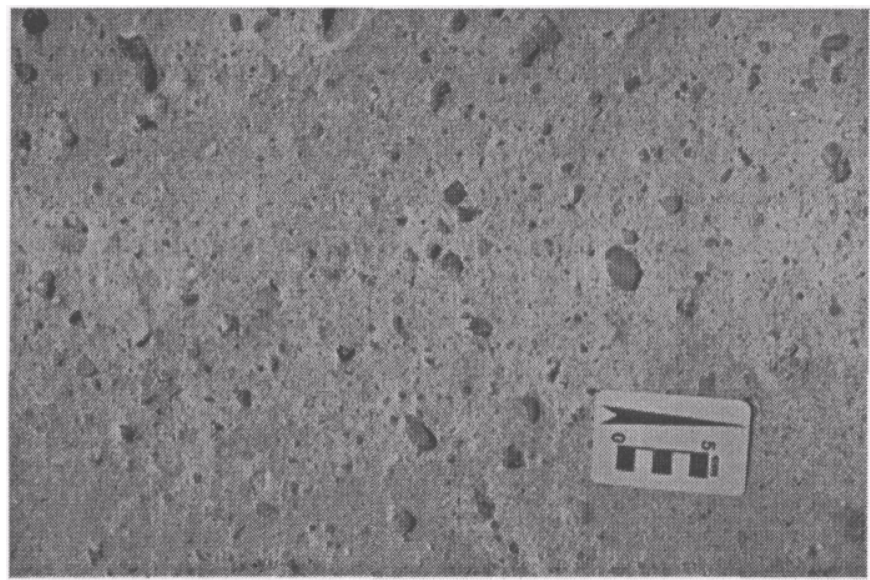

Figura 7 - Fácies Dmm. Observar o aspecto maciço, a seleção e a angulosidade dos clastos. Intervalo intermediário da Formação Vila Maria (ponto 3, Fig. 2).

Fácies Dms(c) - Diamictito estratificado com ação de corrente $\mathrm{Na}$ área de estudo, esta fácies é composta pela intercalação de camadas tabulares de espessura grandede diamictito e de camadas lenticulares de arenito de espessura muito pequena a pequena, de cores cinza e avermelhada. $\mathrm{O}$ arenito apresenta laminação plano-paralela (Fig. 9) ou estratificação cruzada de porte pequeno. Em campo, observa-se uma nítida orientação preferencial dos seixos no diamictito, o que é também observado em lâminas petrográficas, na fração areia. 
Pode-se observar esta fácies na região das cavernas (pontos 4 e 5 , Fig. 2), na antiga estrada para Bom Jardim (ponto 8, Fig. 2) e, principalmente, nas escarpas da fazenda Nossa Senhora de Medianeira (pontos 2 e 3, Fig. 2). Inicialmente esta fácies foi reconhecida como Dmm(c) por Borghi \& Moreira (1996c). Representa dominantemente fluxos gravitacionais subaquosos do tipo fluxo turbidítico arenáceo de densidade alta em um contexto glacial. A intercalação de camadas tabulares de arenitos com laminação plano-paralela ou com estratificação cruzada mostra evidências da ação de correntes de tração, que foram capazes de segregar tais camadas.

$\mathrm{O}$ retrabalhamento por corrente que ocorre subordinado na génese da fácies, é um processo significativo na deposição de muitos diamictitos (Eyles et al. 1983), sendo lags, ondulas e intercalação de camadas retrabalhadas por correntes, como na fácies aqui descrita, componentes importantes.

Fácies Dms(r) - Diamictito estratificado ressedimentado Na área de estudo, esta fácies é composta de um diamictito estratificado, de cores branca e cinza, disposto em conjunto de camadas de espessura muito grande. É caracterizado por apresentar camadas de arenitos deformadas (Fig. 10).

Pode-se observar esta fácies principalmente na área da caverna Aroe Jari (ponto 6, Fig. 2) e nas escarpas próximas (ponto 7, Fig. 2). Representa o produto da ressedimentação por fluxos gravitacionais subaquosos em um contexto glacial. A presença de camadas de arenito deformadas e rompidas evidenciam a fácies original $(\operatorname{Dms}(\mathrm{c}))$ e o caráter de ressedimentação desta fácies. O termo "ressedimentado" é usado por Eyles et al. (1983) para designar diamictitos que mostram evidência de movimento e deposição por fluxos gravitacionais e escorregamentos (slumps) de vários tipos, geralmente próximos a área fonte de sedimentos (Moreira \& Borghi 1998). Estruturas distintas, incluindo flow noses, molde de ranhuras (groove cast) e camadas dobradas por fluxo (flow banding), podem estar presentes (Eyles et al. 1983).

FÁCIES ARENITICAS As fácies areníticas apresentam elevada maturidade composicional, sendo classificados de quartzo-arenitos (sensu Folk et al. 1970). São predominantemente compostos por quartzo, raramente por clastos líticos e chert, e, muito subordinadamente, por zircão, turmalina, muscovita, rutilo, titanita, apatita e minerais opacos O quartzo, principal constituinte do arcabouco dos arenitos, ocorre nas seguintes variedades, em ordem de importância: quartzo monocristalino pouco ou não deformado (predominante), quartzo monocristalino deformado, quartzo policristalino de contatos suturados e poligonizados.

As fácies areníticas que ocorrem estratigraficamente abaixo dos diamictitos apresentam as frações areia fina e silte extremamente angulosas; característica por nós relacionada à abrasão dos clastos na base das geleiras ( $c f$. Eyles \& Eyles 1992).

Fácies Am-Arenito maciço Compõe-se de arenitos finos, maciços, bem selecionados, com grãos subarredondados a arredondados. Dispõem-se em conjunto de camadas maciças de espessura grande a muito grande, com contato plano nítido tanto na base quanto no topo.

A fácies Am ocorre exclusivamente no intervalo basal e intermediário da Formação Alto Garças. É bem observada na localidade próxima à fazenda Serrinha (ponto 9 , Fig. 2) e no morro do Ranchão (pontos 14 e 16, Fig. 2). $\mathrm{O}$ aspecto maciço desta fácies pode refletir processos físicos sedimentares originais ou, como interpretado aqui, ser o resultado da destruição da laminação original por processos imediatamente após a deposição.

Nesta fácies a destruição da laminação foi gerada por intenso retrabalhamento dos sedimentos por organismos bioturbadores, constatado no caso pela presença do icnofóssil Skolithos e por processos de liquefação, constatada pela presença de estruturas associadas ao escape de água, como diques elásticos que ocorrem com dimensões milimétricas na base do perfil próximo a fazenda Serrinha (ponto 9, Fig. 2).

$\mathrm{O}$ aspecto maciço desta fácies também pode estar relacionado à sua seleção granulométrica, pois todo intervalo é constituído de arenitos bem selecionados, sendo pouco provável o desenvolvimento de estruturas evidentes apenas com uma população de grãos.

Fácies At - Arenito em camadas tabulares Compõe-se de arenitos muito finos, finos ou médios, bem selecionados, com grãos subangulosos a arredondados. Ocorre em camadas tabulares de espessura média (15 a $25 \mathrm{~cm}$ ), muito extensas (dezenas de metros) (Fig. 11). Internamente pode ser maciça ou pode apresentar laminação planoparalela ou hummocky/cruzada de baixo-ângulo. O topo pode ser plano

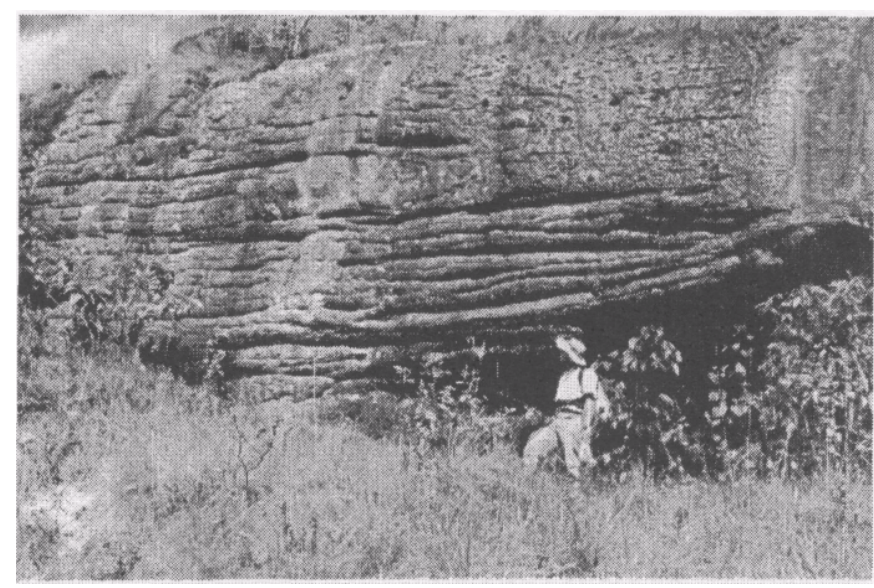

Figura 8 - Fácies Dms. Observar a geometria e o limite dos estratos. Intervalo intermediário da Formação Vila Maria (ponto 2, Fig. 2).

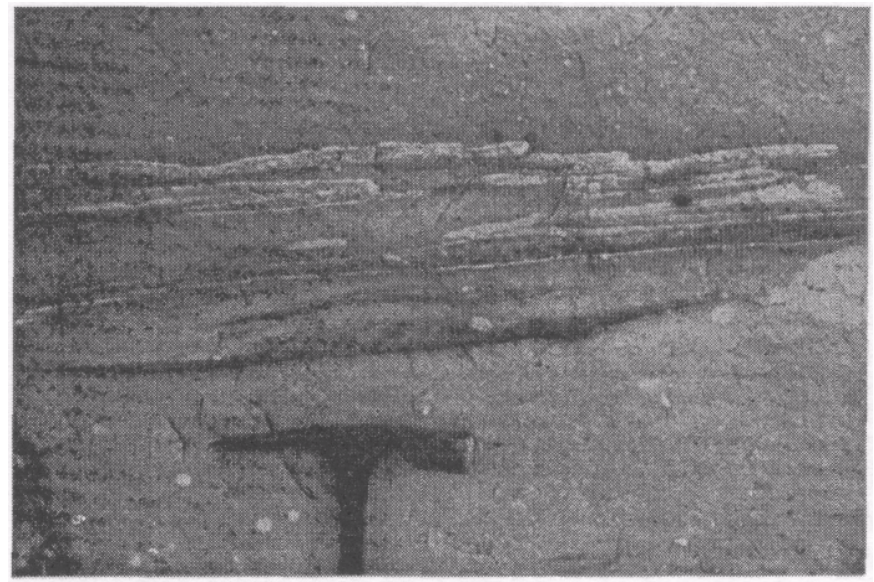

Figura 9 - Fácies Dms(c). Observar a intercalação de arenitos com laminação plano-paralela na fácies de diamictito. Intervalo intermediário da Formação Vila Maria (ponto 8, Fig. 2).

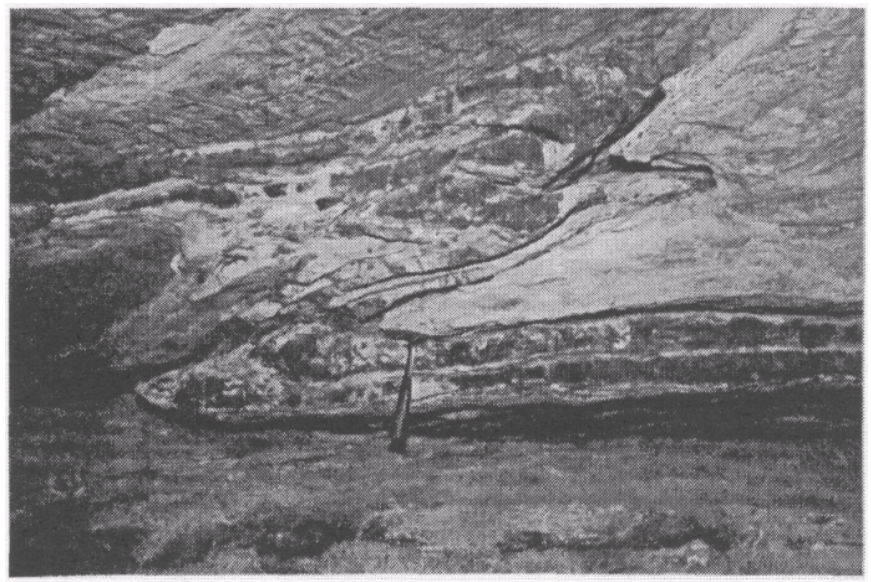

Figura 10. Fácies Dms(r). Observar as camadas deformadas de arenitos nessa fácies. Intervalo intermediário da Formação Vila Maria (ponto 6, Fig. 2).

nítido ou levemente ondulado, enquanto a base apresenta contato plano nítido.

A fácies At ocorre nas formações Alto Garças e Vila Maria. Na Formação Alto Garças, ocorre em toda a sua extensão, sendo bem observada na caverna do Lago Azul (ponto 6, Fig. 2) e escarpas próximas (pontos 3 e 7, Fig. 2) e em Torrinhas (ponto 12, Fig. 2). Na Formação Vila Maria é bem observada no morro do Ranchão (pontos 13, 14 e 16, Fig. 2), ocorrendo também em toda sua extensão. 
Esta fácies é o produto de transporte hidrodinâmico subaquoso por fluxos turbidíticos de densidade alta combinados com oscilações induzidas por tempestades (tempestitos).

A tabularidade e a grande extensão das camadas é utilizada como critério de interpretação desta fácies, bem como da fácies $\mathrm{Ct}$.

A presença de estruturas como laminação plano-paralela e a estratificação cruzada hummocky ou de baixo-ângulo, estruturas típicas da fácies At, são relacionadas a ação de ondas da alta energia (tempestades). N0ttvedt \& Kreisa (1987), no estudo dos fluxos responsáveis pela génese de estratificação cruzada hummocky, apresentam um diagrama de fases conceituai que relaciona vários tipos de fluxos (unidirecional, oscilatório ou combinado entre estes) com a energia e a granulometria.

A fácies At, quando maciça ou laminada, pode ser comparada aos intervalos Ta e Tb da clássica Sequência de Bouma ou às fácies F7 e F8 de Mutti (1992).

A comparação de certos tempestitos com a sucessão clássica de turbiditos de Bouma já fora feita no estudo de sistemas marinhos rasos (Walker \& Plint 1992), onde associam-se as camadas Tb-c de Bouma a uma sucessão de arenito com laminação plano-paralela e de arenito com laminação cruzada de pequeno porte, interpretados como tempestitos.

Fácies Ad - Arenito com laminação cruzada cavalgante Compõe-se de arenitos finos, bem selecionados, com laminação cruzada cavalgante e marcas onduladas assimétricas (Fig. 12). Dispõem-se em camadas lenticulares de espessura pequena a média. Formam conjunto de camadas pouco espessas.

A fácies Ac 1 foi observada apenas na Formação Vila Maria. É muito pouco frequente, ocorrendo apenas na localidade do morro do Ranchão (ponto 14, Fig. 2), podendo ser reconhecida por grandes extensões nesse morro. Esta fácies é o resultado da migração de ondulações assimétricas tridimensionais (linguóides), pela ação de correntes unidirecionais subaquosas trativas de fluxos turbidíticos, em regime de fluxo inferior (Collison \& Thompson 1989). Pode ser comparada ao intervalo Tc da clássica sequência de Bouma ou, em parte, à fácies F9a de Mutti (1992).

Fácies Ac2 - Arenito com estratificação cruzada Compõe-se de arenitos muito grossos, mal selecionados (contém grânulos dispersos), com grãos variando de angulosos a subarredondados, com estratificações cruzadas. Ocorre em camadas lenticulares de espessura média a grande. A base da camada tem caráter erosivo, e o topo apresenta-se plano.

Ocorre no intervalo intermediário da Formação Vila Maria, apenas observada no morro do Ranchão (pontos 14 e 16, Fig. 2). A fácies Ac2 pode ser associada à migração de megaondulações arenáceas, assimétricas, de crista reta ou sinuosa, periódicas, geradas por correntes trativas unidirecionais em condições de energia alta, dentro do campo de fluxo inferior.

Fácies Ao - Arenito com laminação cruzada ondulada Compõe - se de arenitos finos, bem selecionados, com grãos arredondados a subarredondados, com laminação cruzada ondulada e marcas-deonda simétrica. Dispõem-se em conjunto de camadas tabulares e lenticulares de espessura pequena a média, formando conjunto de camadas pouco espessas.

A fácies Ao ocorre exclusivamente na Formação Vila Maria. Podese observá-la na região da fazenda Serrinha (ponto 11, Fig. 2) e no Morro do Ranchão (ponto 14, Fig. 2).

Esta fácies é o produto de fluxos subaquosos oscilatórios (bidirecionais), produzidos pela ação de ondas normais livres de gravidade (cf. DeRaaf et al. 1965). Segundo Collinson \& Thompson (1989), esse padrão oscilatório é importante no movimento dos sedimentos e no desenvolvimento de ondulações simétricas de crista reta, as quais geram, em agradação, a estrutura denominada de laminação cruzada ondulada, como a fácies Ao que a caracteriza. Esta fácies, frequentemente associada à fácies At, que é interpretada como tempestito, corresponde ao retrabalhamento por ondas da tempestade amainada (tempo bom).

Fácies Ao (H) - Arenitos e folhelhos intercalados em acamamento flaser, wavy e linsen Esta fácies, heterolítica, é composta pela intercalação de camadas delgadas ou de lâminas de arenitos fino a muito fino e de folhelhos, em acamamentos dos tipos flaser, wavy e linsen. Dispõem-se em conjunto de camadas com espessura muito grande $(\mathrm{ca} .8 \mathrm{~m})$.

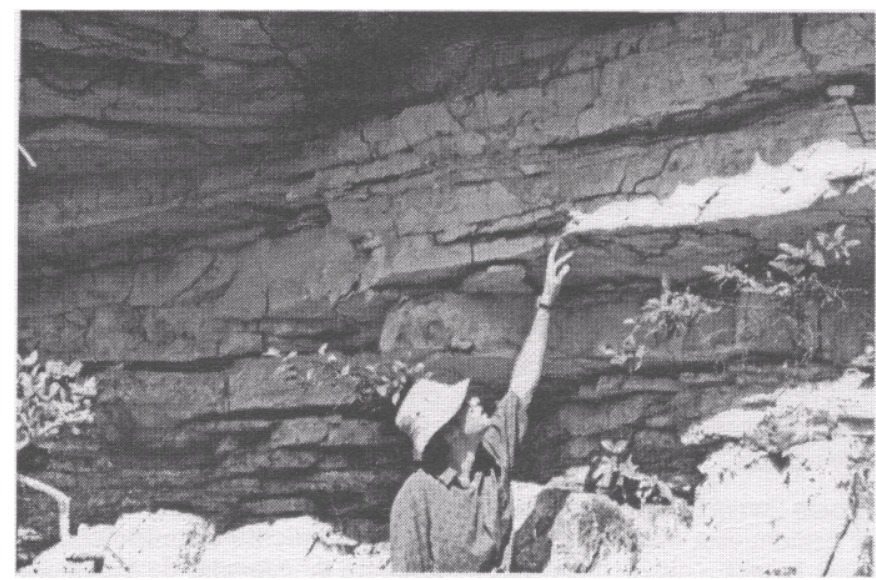

Figura 11 - Fácies At. Observar a tabularidade das camadas. Intervalo de topo da Formação Vila Maria (ponto 14, Fig. 2).

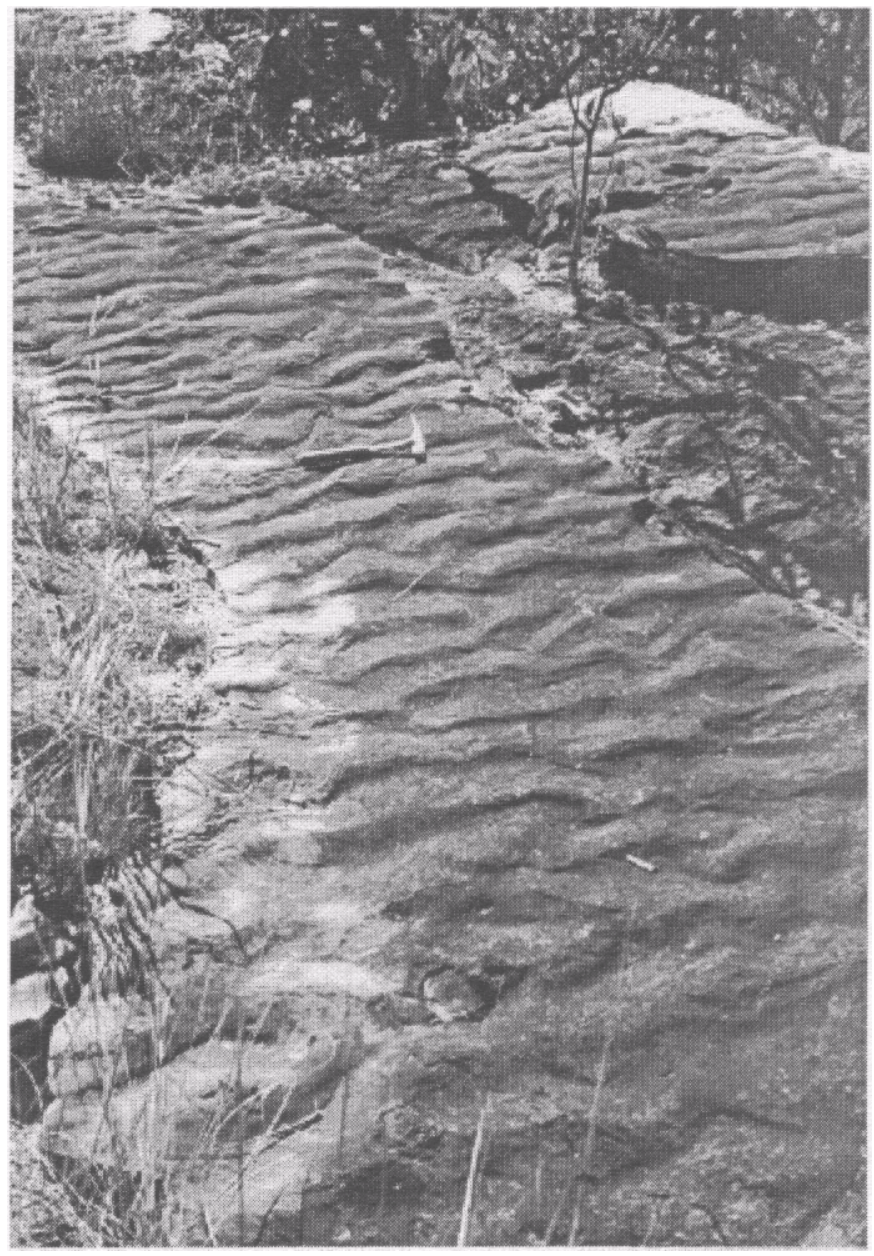

Figura 12 - Fácies Acl. Observar as marcas onduladas assimétricas do tipo linguóides. Intervalo intermediário da Formação Vila Maria (ponto 14, Fig. 2).

A fácies $\mathrm{Ao}(\mathrm{H})$ é restrita à Formação Vila Maria. É muito pouco frequente, tendo sido observada apenas na localidade do morro do Ranchão (ponto 16, Fig. 2).

As estruturas/toser, wavy e linsen, presentes nesta fácies, implicam que tanto areia quanto argila estavam disponíveis no ambiente e que há alternância de períodos de maior energia (ação de correntes ou ondas) e de calmaria (decantação). Durante os períodos de maior energia, as areias eram transportadas e depositadas como marcas onduladas, enquanto as arguas era mantida em suspensão. Cessando a corrente, a argila em suspensão depositam-se principalmente nas calhas ou cobrindo completamente as marcas onduladas. 
Fácies lutítica - Fácies Fld - Folhelho com clastro caído Esta fácies, definida por Eyles et al. (1983), compõe-se, na região, de folhelhos em diversos tons de cinza, bem laminados e físseis, com clastros caídos. Os seixos são compostos de quartzo, subarredondados, e apresentam tamanho máximo de $5 \mathrm{~cm}$. Ocorrem também pequenos níveis com grãos de areia formando lâminas milimétricas. Apresenta espessura de 4 a 8 metros.

A fácies Fld é encontrada apenas na Formação Vila Maria, sendo bem observada no morro do Ranchão (pontos 14 e 16, Fig. 2) e em localidades próximas à fazenda Serrinha (ponto 10, Fig. 2).

Esta fácies é produto de processos de decantação de sedimentos finos em suspensão em um contexto glacial distai. Sua deposição ocorre em ambientes de baixa energia. Os clastros caídos e as lâminas arenáceas milimétricas são derivados de ice-rafted glacial, os quais são transportados por icebergs (Eyles et al. 1983).

Icnofácies Os icnogêneros identificados que caracterizam as icnofácies são: Arenicolites Salter 1857, Arthrophycus Hall 1852, Aulichnites Fenton \& Fenton 1937, Chondrites von Sternberg 1833, Diplocraterion Torell 1870, Lockeia James 1879, Palaeophycus Hall 1847, Skolithos Haldeman 1840 e Teichichnus Seilacher 1955. Para todo o intervalo, foram identificadas duas icnofácies: Skolithos e Cruziana. No caso da Formação Alto Garças, por exemplo, chegam a caracterizar a principal fácies sedimentar, o que os torna um aspecto muito importante na análise de fácies para interpretação e reconstrução dos paleoambientes deposicionais.

FÁCIES SKO - SKOUTHOS Na icnofácies Skolithos identificada na área de estudo, ocorrem duas icnocomunidades distintas: uma, representada apenas pelo icnofóssil Skolithos linearis Haldeman 1840, e, a outra, por S. linearis, Arenicolites ichnosp. e Diplocraterion ichnosp.

A fácies Skolithos é característica da Formação Alto Garças, sendo a única que nela ocorre, e é representada apenas pelo icnofóssil Skolithos linearis (Fig. 13). A fácies Skolithos na Formação Vila Maria apresenta duas icnocomunidades distintas. Uma é caracterizada somente pela presença de 5. linearis e, a outra, por S. linearis, Arenicolites ichnosp. e Diplocraterion ichnosp.

A fácies SKO da Formação Alto Garças pode ser bem observada nas localidades de Torrinhas (ponto 12, Fig. 2), morro do Ranchão (ponto 17, Fig. 2) e na caverna do Lago Azul (ponto 6, Fig. 2). Na Formação Alto Garças, estende-se da base ao topo, com índices de icnotrama 4,5 e 6 de Bottjer \& Drosser (1991), sendo os dois primeiros considerados piperock (sensu Peach \& Horne 1884 apud Bottjer \& Drosser 1991). Segundo Moreira et al. (1991), a formação do piperock na Formação Alto Garças requereu tempo suficientemente longo para a colonização do substrato arenoso por uma icnofauna, o que reflete baixas taxas de erosão e sedimentação (baixa taxa de agradação de estratos).

Na Formação Vila Maria, a fácies SKO, caracterizada apenas por 5. linearis apresenta índice da icnotrama 5, enquanto a outra, caracterizada por S. linearis, Arenicolites ichnosp. e Diplocraterion ichnosp., apresenta índices de icnotrama 2. A primeira, observada em uma única localidade próxima a fazenda Serrinha (ponto 11, Fig. 2), é restrita ao intervalo intermediário; enquanto que, a segunda icnocomunidade, bem observada na localidade do morro do Ranchão (ponto 14 Fig. 2), é restrita ao intervalo de topo.

Em estratos do Paleozóico Inferior, a icnofácies Skolithos é característica de ambiente marinho de alta energia, geralmente sob ação de ondas em águas rasas, em regiões costeiras de face-de-praia e antepraia, com sedimentos arenáceo finos bem selecionados (Frey \& Pemberton 1984).

FÁCIES CRZ - CRUZIANA Na icnofácies Cruziana identificada na área de estudo, ocorrem duas icnocomunidades distintas: uma, representada pela associação dos icnofósseis Arthrophycus alleghaniensis (Harlan 1831) Hall 1852 (Fig. 14), Palaeophycus tubularis Hall 1847, Aulichnites ichnosp. e Lockeia ichnosp., e, a outra, por Chondrites ichnosp. e Teichichnus ichnosp.

A fácies CRZ ocorre exclusivamente na Formação Vila Maria. A icnocomunidade representada por A. alleghaniensis, $P$. tubularis, Aulichnites ichnosp. e Lockeia ichnosp. foi observada no intervalo de base e intermediário no perfil do morro do Ranchão (pontos 13,14,15 e 16, Fig. 2), e de base na caverna do Lago Azul (ponto 6, Fig. 2) e escarpas próximas (ponto 7, Fig. 2). A outra icnocomunidade, representada pelos icnofósseis Chondrites ichnosp. e Teichichnus ichnosp. ocorre no intervalo intermediário da formação, e foi bem observada próximo à fazenda Serrinha (ponto 10, Fig. 2).
As duas icnocomunidades descritas na área de estudo levam a duas interpretações paleoambientais distintas possíveis para fácies CRZ, a qual apresenta um contexto de ambiente marinho raso (Frey \& Pemberton 1984). São de diferentes contextos sedimentológicos, porém estão de acordo com a definição da icnofácies Cruziana. A primeira icnocomunidade, representada pelos icnofósseis $A$. alleghaniensis, $P$. tubularis., Aulichnites ichnosp. e Lockeia ichnosp., compreende ambientes litorâneos (antepraia inferior) de águas mais profundas que a da icnofácies Skolithos, abaixo da linha de rebentação, na região sob ação de ondas e correntes normais (tempo bom) e, eventualmente, de tempestade, sobre substrato arenáceo. A segunda icnocomunidade, representada por Chondrites ichnosp. e Teichichnus ichnosp., indica a colonização de um substrato lutáceo de pouca mobilidade, de águas

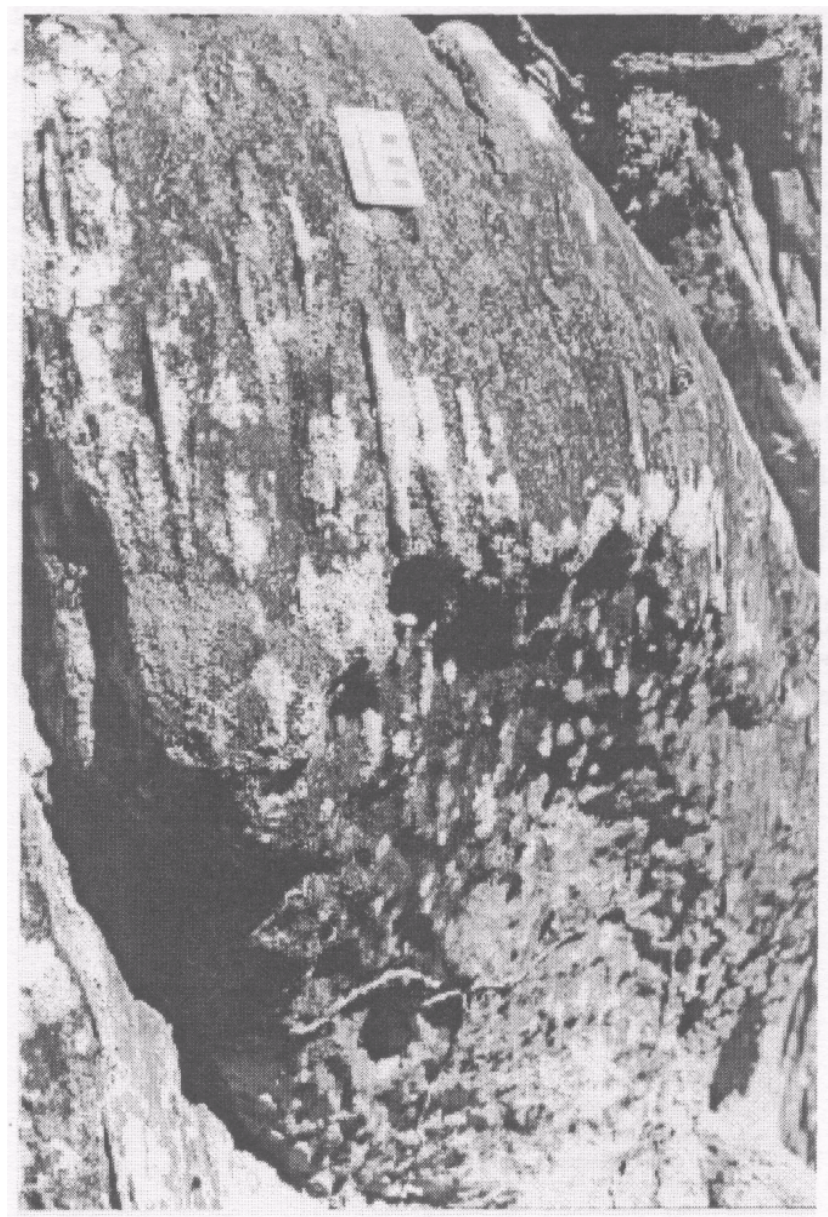

Figura 13 - Fácies SKO, caracterizada por Skolithos linearis. Formação Alto Garças (ponto 17, Fig. 2).

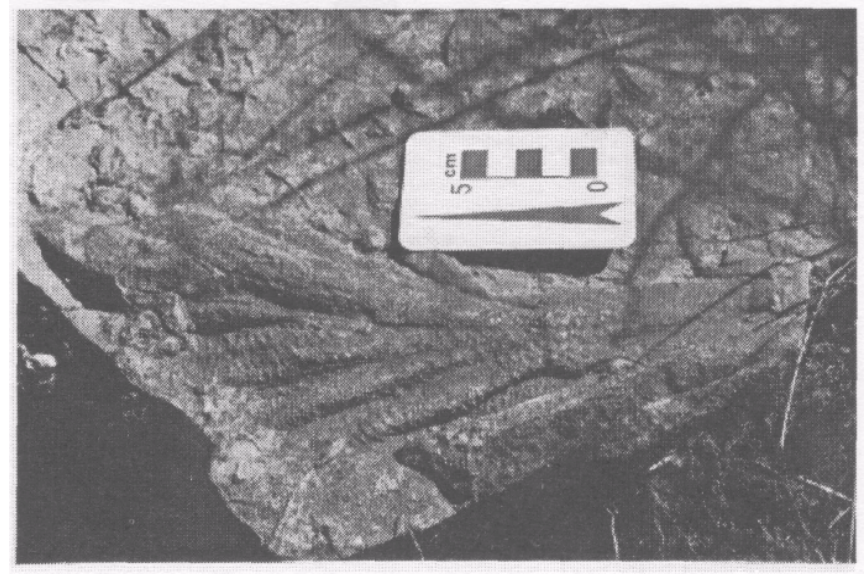

Figura 14 - Fácies CRZ, caracterizada por Arthrophycus alleghaniensis. Intervalo intermediário da Formação Vila Maria (ponto 16, Fig. 2). 
mais profundas e tranquilas que a icnocomunidade acima, compreendendo a transição do ambiente marinho de antepraia para o de costaafora, sob eventual ação de correntes e ondas de tempestade.

SISTEMAS DEPOSICIONAIS Um sistema deposicional é definido como uma assembleia tridimensional de fácies geneticamente ligadas por processos e ambientes ( $c f$. Fisher \& McGowen 1967). Assim, a partir das fácies anteriormente descritas foram reconhecidos quatro sistemas deposicionais que caracterizam toda a sucessão estratigráfica ordovício-siluriana da região de Chapada dos Guimarães (Fig. 15).

Sistema Fluvial -SF O sistema fluvial é representado por conjuntos de camadas da fácies $\mathrm{Ce}$. O conjunto de camadas desta fácies apresenta geometria de canais rasos e largos (Fig. 16) em uma sucessão vertical de cerca de $3 \mathrm{~m}$ de espessura. Ocorre na base da Formação Vila Maria e pode ser observado no perfil de Torrinhas (ponto 12, Fig. 15) e no perfil do Morro do Ranchão (ponto 17, Fig. 15).

A fácies Cc, que compõe o sistema fluvial aqui descrito, pode ser comparada à fácies Gp de Miall (1996), interpretada como o resultado da migração barras transversais em um sistema fluvial rudáceo. Apesar de sua reduzida seção, o sistema fluvial aqui proposto parece assemelhar-se com a sucessão fluvial do tipo Scott de Miall (1977) ou ao modelo 2 de Miall (1985), associados a correntes derivadas do degelo nas porções marginais das geleiras que fluem através de rios entrelaçados de outwash plains (Collinson \& Thompson 1989, Eyles \& Eyles 1992, Miall 1992). Esta associação é corroborada pelo contexto glacial, apontado na sucessão estratigráfica característica da região.

Sistema marinho raso rudáceo - SMRrud O sistema marinho raso rudáceo compreende os ambientes de face-de-praia e de antepraia proximal e distai.

$\mathrm{O}$ ambiente marinho de face-de-praia é caracterizado por um conjunto tabular de camadas da fácies $\mathrm{Ct}(\mathrm{H})$, com espessura de até $2 \mathrm{~m}$. Ocorre no intervalo basal da Formação Vila Maria e pode ser bem observado no perfil de Torrinhas (ponto 12, Fig. 15). A fácies $\mathrm{Ct}(\mathrm{H})$, gerada pelo espraiamento marinho (swash e backswash), pode ser comparada aos depósitos de face-de-praia rudáceas do Recente de Keulenfjorden (Spitsbergen, Canadá) e do Pleistoceno de Cape Blanco (Oregon, EUA), descritos por Nemec \& Steel (1984) e Bourgeois \& Leithold (1984).

$\mathrm{O}$ ambiente marinho de antepraia proximal rudáceo é caracterizado por uma sucessão composta pela intercalação de camadas das fácies Ct e At (Fig. 17), por vezes apresentando um ciclo de afinamento granulométrico ascendente em um intervalo de cerca de $5 \mathrm{~m}$ de espessura. Ocorre no intervalo basal da Formação Vila Maria e pode ser bem observada na saída sul da caverna Aroe Jari (ponto 6, Fig. 2). Este ambiente é dominado por correntes e ondas induzidas por tempestades que transportam os sedimentos grossos. Essas são responsáveis pelo transporte e deposição por fluxos turbidíticos e posterior retrabalhamento por fluxos oscilatórios (presença de megaondulações no topo de algumas camadas da fácies $\mathrm{Ct}$ ). A fácies $\mathrm{Ct}$ é o produto da reelaboração de depósitos de origem fluvial, responsáveis pelo aporte desses sedimentos no ambiente marinho, pela ação dessas tempestades A fácies Ct pode ser comparada à fácies de conglomerado de ambiente de antepraia proximal descrita por Bourgeois \& Leithold (1984), que, como a fácies $\mathrm{Ct}$, é suportada por clastos, dispostas em camadas tabulares muito extensas, com base plana e topo retrabalhado em formas de megaondulações. A fácies At também representa depósitos relacionados a tempestades. Essas fácies ( $\mathrm{Ct} \mathrm{e} \mathrm{At}$ ) assemelham-se às fácies de antepraia proximal descritas por Bourgeois \& Leithold (1984) nos depósitos do Mioceno de Floras Lake e Cape Sebastian (Oregon, EUA).

$\mathrm{O}$ ambiente marinho de antepraia distai corresponde a um conjunto de camadas da fácies At com icnofósseis da icnocomunidade de Arthrophycus alleghaniensis, Palaeophycus tubularis, Aulichnites ichnosp. e Lockeia ichnosp. da fácies CRZ, compondo seções de até 10 metros de espessura. Subordinadamente, ocorrem camadas da fácies Ct com espessura pequena e camadas da fácies Ac2. Ocorre no intervalo intermediário da Formação Vila Maria e pode ser bem observado no perfil do morro do Ranchão (ponto 14, Fig. 15). A fácies Crz, característica do ambiente de antepraia distai, é associada a ambientes litorâneos de energia relativamente moderada a baixa,
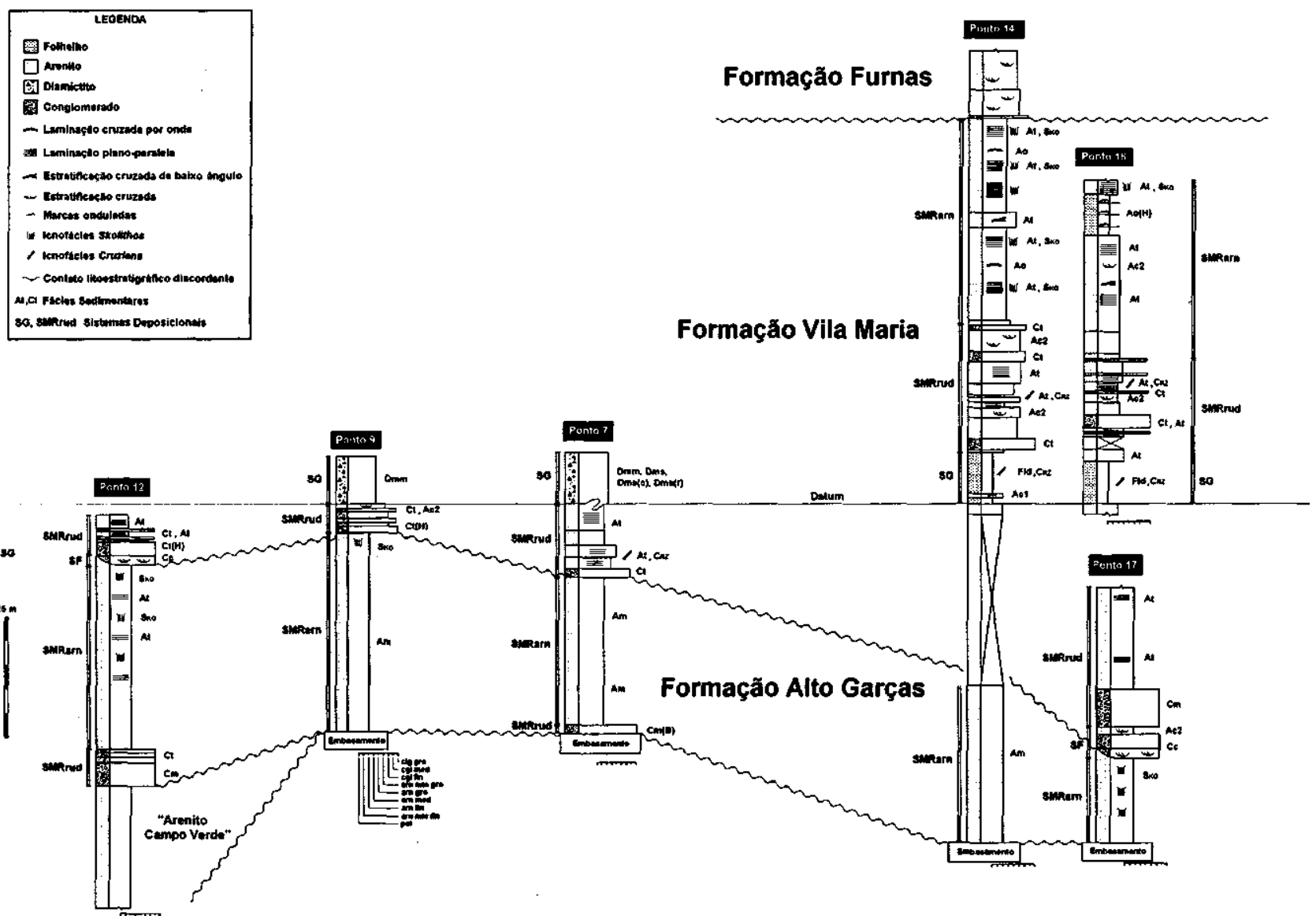

Figura 15 • Perfis sedimentográficos com a indicação das fácies sedimentares e sistemas deposicionais. Como datum de correlação tomou-se a base dos depósitos glaciais. 
abaixo da linha de rebentação das ondas normais, na região sob ação de tempestade, em substrato arenáceo. As tempestades disparariam os fluxos responsáveis pela deposição das camadas da fácies At e $\mathrm{Ct}$, que, posteriormente, com o decréscimo de energia, seriam retrabalhadas por orga-nismos, gerando a fácies CRZ dessa associação. As tempestades também retrabalhariam o topo das camadas das fácies Ac2, que correspondem a barras subaquosas desenvolvidas na plataforma.

Sistema marinho raso arenáceo - SMRarn O sistema marinho raso arenáceo compreende os ambientes lagunar e de antepraia proximal. $\mathrm{O}$ ambiente lagunar é caracterizado por uma sucessão de camadas da fácies $\mathrm{Ao}(\mathrm{H})$ com icnofósseis da fácies SKO, e camadas da fácies Ac 1 . O conjunto de camadas das fácies apresenta geometria lenticular em uma sucessão vertical de cerca de $8 \mathrm{~m}$ de espessura. Ocorre no intervalo de topo da Formação Vila Maria, tendo sido observada apenas na localidade do morro do Ranchão (ponto 16, Fig. 15). Este ambiente, identificado pela associação das fácies SKO e $\mathrm{Ao}(\mathrm{H})$, é interpretado como o produto da alternância de períodos de maior energia nas margens das lagunas (fácies $\mathrm{Ao}(\mathrm{H})$ com acamamento flaser) e calmaria (fácies $\mathrm{Ao}(\mathrm{H})$ com acamamento linsen). A fácies $\mathrm{Ao}(\mathrm{H})$ representa o retrabalhamento das areias transportadas por fluxos turbidíticos induzidos por tempestades (fácies Acl) para o interior da laguna, talvez associado ao arrombamento das ilhas de barreira, não preservadas, por leques de washover.

$\mathrm{O}$ ambiente de antepraia proximal é composto principalmente pela intercalação das fácies At com icnofósseis da fácies SKO em maior ou menor índice de icnotrama (Fig. 18). Subordinadamente, ocorrem camadas da fácies Ao, como observado na Formação Vila Maria, e camadas da fácies Am, como pode-se observar na base da Formação Alto Garças. Essa sucessão é característica da Formação Alto Garças estando representada em toda sua extensão. No intervalo de topo da Formação Vila Maria pode chegar a cerca de $40 \mathrm{~m}$ de espessura, podendo ser bem observada no perfil de Torrinhas (ponto 12, Fig. 15) e na caverna do Lago Azul (ponto 6, Fig. 2). A fácies SKO, característica da sucessão de antepraia proximal arenítica, é associada a ambiente marinho de alta energia, sob ação de ondas em regiões marinhas rasas (Frey \& Pemberton 1984). Eventuais fluxos turbidíticos induzidos por tempestades seriam responsáveis pela deposição de espessas sucessões de camadas da fácies At, que posteriormente seriam retrabalhadas por organismos, gerando a fácies SKO ou Am, ou por ondas normais (fácies Ao). A fácies Am representa possivelmente uma variação lateral da fácies SKO, com um índice de icnotrama (ii)6, e/ou associado a processos de liquefação. A fácies Ao é o registro da ação das ondas normais livres. A sucessão de fácies de antepraia proximal da Formação Vila Maria difere da sucessão de fácies da Formação Alto Garças por apresentar índice de icnotrama inferior, o que reflete altas taxas de sedimentação que impossibilitam uma maior colonização do substrato por uma icnofauna.

Sistema Glaciomarinho -SG O sistema glaciomarinho, carac-terizado pela associação das fácies Fld, Acl, Crz, Dmm, Dmm(r), Dms, Dms(c) e Dms(r), pode ser organizado em duas sucessões distintas. Essas duas sucessões caracterizam um ambiente glaciomarinho proximal, dominado por processos glaciais, e outro distai, dominado por processos marinhos.

O ambiente glaciomarinho proximal é representado por camadas das fácies Dmm, Dms, Dms(r) e Dms(c), compondo seções de até 10 $\mathrm{m}$ de espessura. Apresenta uma grande variação lateral e vertical das fácies em questão e nem sempre é possível de se estabelecerem sucessões verticais de fácies. Espacialmente, as fácies Dms e Dms(c) encontram-se mais abundantes na região noroeste da área, enquanto que as fácies Dmm e Dms(r), apesar de terem sido descritas em todos os pontos, apresentam-se abundantes na região sudeste da área. Ocorre no intervalo intermediário da Formação Vila Maria e pode ser bem observado nas escarpas da fazenda Medianeira (pontos 2 e 3, Fig. 2) e na região das cavernas e escarpas próximas (ponto 7, Fig. 15). Os processos responsáveis pela deposição das fácies de diamictitos aqui descritas são característicos do ambiente glaciomarinho proximal dominado pela ação direta do gelo (Eyles \& Eyles 1992). Os diamictitos maciços e estratificados depositam-se por fluxos gravitacionais do tipo fluxo-de-detritos associados à chuva de detritos (fácies Dmm) ou turbidítico (fácies Dms), como pulsos densos e episódicos derivados de águas de degelo carregadas de sedimentos. Diamictitos intercalados com camadas de areia podem acumular-se em episódios de ação de correntes trativas, por fluxos turbidíticos de densidade alta (fácies Dms(c)). Ressedimentação por escorregamentos gravitacionais subaquosos são um processo ativo nas proximidades das geleiras

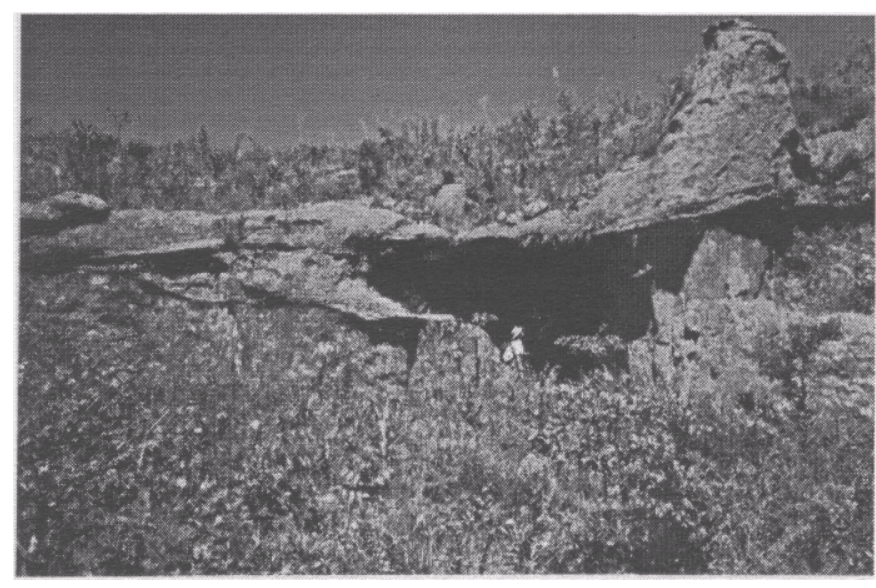

Figura 16. -Sistema fluvial-SF. Observar a geometria de canal. Base da Formação Vila Maria (ponto 12, Figs. 2 e 15).

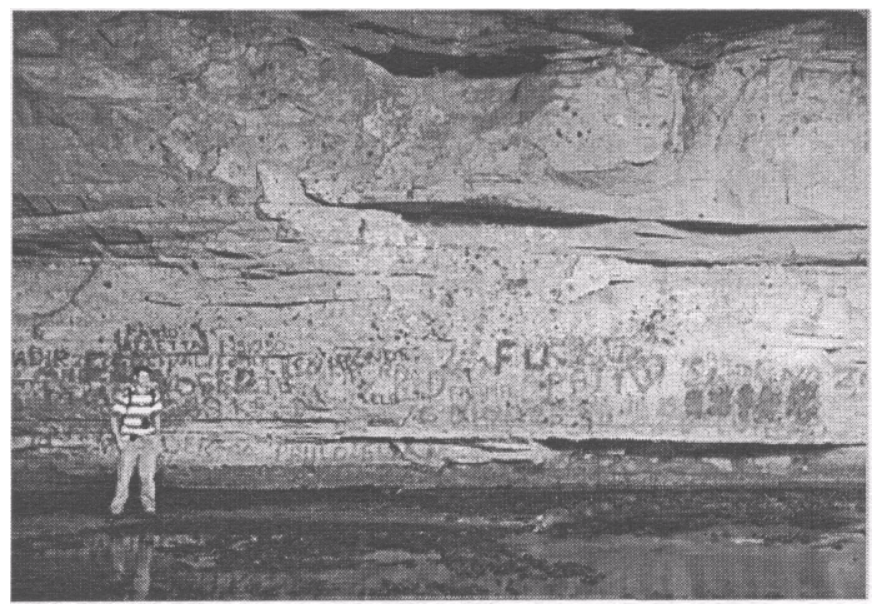

Figura 17 - Aspecto de campo do sistema marinho raso de antepraia proximal rudácea - SMRrud. Observar a tabularidade e extensão das camadas da fácies CteAt. Intervalo de base da Formação Vila Maria (ponto 6, Fig. 2).

(Eyles et al. 1985) e fornecem diamictitos com camadas de arenitos deformados (Dms(r)), segundo Eyles et al. (1993).

O ambiente glaciomarinho distai é caracterizado por uma sucessão de camadas da fácies Fld com icnofósseis da fácies CRZ da icnocomunidade de Chondrites ichnosp. e Teichichnus ichnosp. e, subordinadamente, pela fácies Acl. A fácies Dmm(r) foi observada em um único ponto na região sudeste da área, associando-se à fácies Fld. Apresenta - se principalmente como um conjunto de camadas homogéneas da fácies Fld, compondo seções de $8 \mathrm{~m}$ de espessura. Ocorre no intervalo intermediário da Formação Vila Maria e pode ser bem observada no perfil do morro do Ranchão (ponto 14 e 16, Fig. 15) e na região da fazenda Serrinha (ponto 11, Fig. 2). As fácies Fld, CRZ e Dmm(r), típicas deste ambiente, são dominadas por processos marinhos (Eyles \& Eyles 1992). A fácies Fld é interpretada como o produto da decantação de sedimentos finos em suspensão em um contexto glacial de pouca energia. A influência glacial é representada pelos clastro caído da fácies Fld, que seriam depositados por ice-rafted derivados de icebergs e pela fácies de Dmm(r), que representa a deposição por fluxos-de-detritos subaquosos resultante da ressedimentação por escorregamentos de sedimentos, em um ambiente marinho mais profundo que as outras fácies de diamictito, dada a sua associação com a fácies Fld. A fácies CRZ representa a colonização de um substrato lutáceo (fácies Fld) de pouca mobilidade em águas relativamente profundas, abaixo da ação de ondas, compreendendo o ambiente costa-afora, sob eventual ação de corrente derivadas de pulsos de degelo (fácies Acl).

CONSIDERAÇÕES FINAIS A sucessão estratigráfica da Formação Alto Garças, interpretada como um sistema marinho raso 


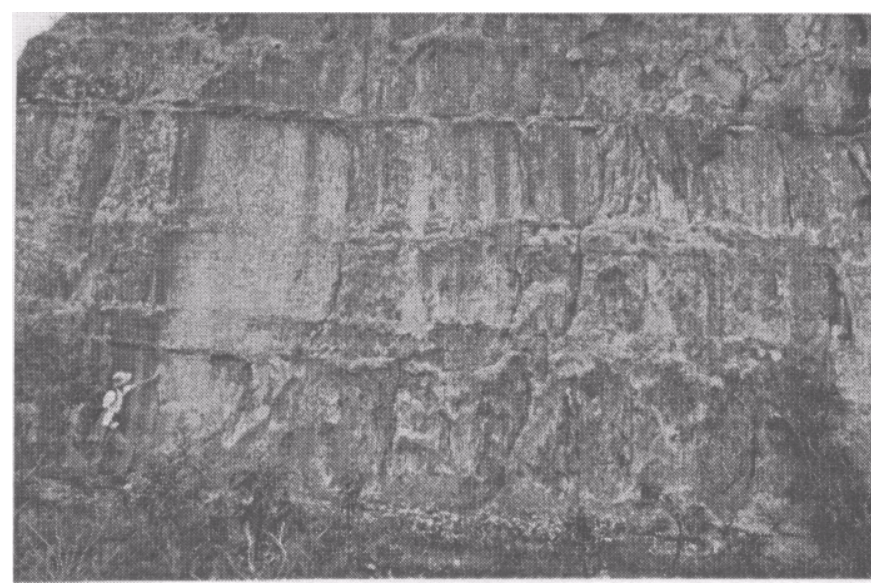

Figura 18 - Sistema marinho raso de antepraia proximal arenáceo SMRarn. Observar a intercalação de camadas das fácies At e SKO. Formação Alto Garças (ponto 12, Figs. 2 e 15). arenáceo (SMRarn), está sugestivamente contida em um trato de sistemas de mar alto (TSMA), dentro de uma sequência de tipo 1 (sensu van Wagoner et al. 1988), ordoviciana.

Sobreposta a essa sucessão, em discordância de tipo 1 ( $c f$. Borghi \& Moreira 1997), produzida pela queda eustática do nível do mar relacionada à fase de máximo glacial na bacia, ocorrem os depósitos rudáceos do sistema fluvial (SF) da base da Formação Vila Maria, que representam a cicatrização do ravinamento do relevo na fase inicial da transgressão marinha, em virtude da deglaciação. Sobreposto ao SF, ocorrem em sucessão um sistema marinho raso rudáceo (SMRrud) e um sistema glaciomarinho (SG), este contendo a superficie de inundação máxima (SIM, fácies Fld). O SF, o SMRrud e o SG compõem o trato de sistema transgressivo (TST). Sobre a SIM, sucedem-se novo SMRrud e um SMRarn que representam o TSMA implantado na bacia depois da fase transgressiva, pós-glacial. Estes tratos de sistema (TST e TSMA) compõem uma sequência ordovício-siluriana, que é representada pela Formação Vila Maria.

Agradecimentos À Faperj pela concessão de bolsa de Apoio Técnico, à Sub-reitoria de Ensino para Graduados e Pesquisa (SR-2) da UFRJ e à FUJB pelo apoio financeiro ao projeto; ao $12^{\circ}$ Distrito do DNPM (MT) pela cessão de viatura de campo e motoristas; à CPRM/DIDOTE pela cessão de fotografias aéreas do Projeto 63-32USAF e a dois revisores anónimos da RBG pelas sugestões e críticas.

\section{Referências}

Agcr D.V. 1974. Slorm deposils in the Jurassic of the Moroccan High Alias. Paleogeogmphy, Paleoclimatology, Paleoecology, 15:83-93.

Assine M.L. \& Soares P.C. 1989. Correlações das sequências mcsopalco/óicas da bacia do Paraná. Acta Geológica Leopoldense, 12:3918.

Assine M.L.. Soares P.C., Milani E.J. 1994. Sequências leclono-scdimcntarcs mesozóicas da bacia do Paraná, Sul do Brasil. Revista Brasileira de Geociências, 24:77-89.

Borghi L. \& Moreira M.I.C. 1996a. Sucessões scdimenlarcs pré-dcvonianas da bacia do Paraná na Chapada dos Guimarães, Eslado de Mato Grosso. Anais da Academia brasileira de Ciências., 68:276.

Borghi L. \& Moreira M.I.C. 1996b. A ocorrência inédita do sistema Ordoviciano na bacia do Paraná, em afloramentos de seu bordo Noroeste. In: Congresso Brasileiro de Geologia, 39, Salvador, 1996. Anais... Salvador, SBG, v.1, p. 145-147.

Borghi L. \& Moreira M.I.C. 1996c. Aspectos petrológicos dos diamictitos das formações lapó c Vila Maria (bacia do Paraná). In: Congresso Brasileiro de Geologia, 39., Salvador, 1996. Anais... Salvador, SBG v.1, p. 149-151.

Borghi L. \& Moreira M.I.C. 1997. O limite das formações Alto Garças (Ordoviciano) e Vila Maria (Siluriano), na borda Noroeste da bacia do Paraná. In: Simpósio sobre Cronocstraligrafia da Bacia do Paraná, 3, Barra do Garças, MT. Boletim de Resumo. Expandidos...Rio de Janeiro, Faculdade de Geologia da Uerj-Editora da Ucrj, p. 4-5.

Borghi L. \& Moreira M.I.C. 1998a. Conlribuição ao conhccimcnlo do Palco/.óico Inferior da bacia do Paraná: mapcamenlo geológico da região Oriental de Chapada dos Guimarães, Estado de Mato Grosso. A Terra em Revista, 4:22-31.

Borghi L. \& Moreira M.IC. 1998b. Um possível intervalo cstratigráfico sob a Formação Alto Garças (bacia do Paraná), no Estado de Mato Grosso. Anais da Academia Brasieira de Ciências. 70:152.

Borghi L., Moreira M.I.C., Fernandes A.C.S. 1996. A ocorrência do icnogênero Arthrophycus Hall, $1852 \mathrm{~cm}$ Chapada dos Guimarães, Estado de Mato Grosso. Anais da Academia Brasieira de Ciências, 68:274-275.

Borghi L., Moreira M.I.C., Fernandes A.C.S. 1997. Icnotramas da Formação Alto Garças (Ordoviciano) na análise cronoestratigráfica. In: Simpósio sobre cronocstratigrafia da bacia do Paraná, 3, Barra do Garças, MT. Boletim de Resumos Expandidos...Rio de Janeiro, Faculdade de Geologia da Ucrj-Editora da Ucrj, p. 3-4.

BottjerD.J. \& Drosser M.L. 1991. Ichnofabric and basin analysis. Palaios, 6:199-205.

Bourgeois J. \& Lcithold E.L. 1984. Wavc-workcd conglomcratcs - Deposilional processes and criteria forrccognition. In: Kostcr E. H. \& Slccl R. J. (cds.) Sedimentology of graveis and conglomcrales, Canadian Society of Petroleum Geologists, Memoir, 10:331-344.

Clifton H.E., Huntcr R.E., Phillips R.L. 1971. Depositional structurcs and processes in the non-barrcd, high-cnergy ncarshorc. Journal of Sedimentar)' Petrology, 41:651-670.

Collinson J.D. \& Thompson D.B. 1989. Sedimentar)' structures. 2.cd. London, Georgc Allen \& Unwin, 194p.

de Raaf J.F.M., Reading H.G., Walkcr R.G. 1965. Cyclic scdimentation in lhe Lower Wcstphalian of North Devon, England. Sedimentology, 4:1-52

Eyles N. \& Eyles C.H. 1992. Glacial depositional systcms. In: Walker R. G. \& James N. P. (eds.) Fácies Models: response to sea levei change. Ontario, Geological Association of Canada, p. $73-100$.

Eyles N., Eyles C.H., Miall A.D. 1983. Lithofacies types and vertical profile models; an alternativc approach to the description and cnvironmental interpretation of glacial diamict and diamictitc scquencc. Sedimentology, 30:393-410.

Eyles N, Eyles C.H., Miall A.D. 1985. Models of glaciomarinc scdimentation and their application to the intcrpretation of ancient glacial scquenccs. Palaeogeography, Palaeoclimatology, Palaeoecology, 51:15-84.

Eyles C. H., Eyles N., França A.B. 1993.Glaciationand tcctonicsinan active intracratonic basin: the late Palcozoic Itararé Group, Paraná basin, Brasil. Sedimentology, 40:1-25.

Faria A. 1982. Formação Vila Maria - nova unidade litoestratigráfica siluriana da bacia do Paraná Ciências da Terra, 3:12-15.

Fisher W.L. \& McGowen J.H. 1967. Dcpositional systems in the Wilcox Group of Texas and their relationship to occurencc of oil and gás. Gulf Coastal Association of Geological Societics, Transactions, 17:105-125.

Folk R.L., Andrews P.B., Lewis D.W. 1970. Detrital sedimentary rock classification and nomenclature for use in New Zeland. New Zeland Journal of Geology \& Geophysics, 13:937-968.

Frey R.W. \& Pcmberton S.G. 1984. Trace-fossil fácies models. In: Walkcr R.G. (cd.) Fácies models. Ontario, Gcological Association of Canada, p. 189-207.
Gray J.,ColbathG.K., Boucot A., RohrD.M. 1985. Silurian-agcfossils from the Palco/oic Paraná Basin, southren Bra/.il. Geology, 13:521-525.

Grahn Y. 1992. Revision of Silurian and Devonian strata of Brazil. Palinology, 16:35-61.

Lcckic D.A. \& Walker R.G. 1982. Storm- and tidc-dominated shorelines in Crctaccous Mooscber-Lower Gatcs Intcrval -outcrop cquivalcnts of deep basin gás traps in western Canada. American Association of Petroleum Geologists Bulletin, 66:138-157.

Lowc D.R. 1982. Scdiment gravity flows. II. Depositional models with spccial rcfercnce to the deposits of high-density turbidity currenls. Journal of Sedimentary Petrology, 51:279-297.

Maack R. 1947. Breves notícias sobre a geologia dos estratos do Paraná c Santa Catarina. Curitiba, Arquivos de BIOLOGIA c TECNOLOGIA (IBPT), II:63-154.

Machado, M.D.C., Kotzian C., Borghi L, Moreira M.I.C. 1997. Sobre a ocorrência do género Brasileiro de Paleontologia, 15, São Pedro, 1997. Boletim... São Pedro, UNESP, p. 63.

Miall A.D. 1977. A rcvicw of the braidcd-rivcr depositional enviroments. Earth-Science Review, 13:1-62.

Miall A.D. 1985. Architcctural-elcment analysis: a new method of fácies analysis applied to fluvial deposits. Earth-Science Review, 22:261-308

Miall A.D. 1992. Alluvial Deposits. In: Walker R. G. \& James N. P. (eds.) Fácies models: Responses to sea levei change. Ontario, Gcological Association of Canada, p. 119-142.

Miall A.D. 1996. The gcology of fluvial dcposits: sedimentary fácies, hasin analysis, and

Moreira, M.I.C. \& Borghi, L. (1999). Revisão cstratigráfica do intervalo Ordoviciano-Siluriano da bacia do Paraná. Anais da Academia Brasileira de Ciências, 71(4-I):743-766.

Moreira M.I.C. \& Borghi L. 1997. Contribuição ao conhecimento geológico da Chapada dos Guimarães, Mato Grosso: o registro do Paleozóico Inferior. An. Acad. bras. Ci., 69(1):139-140.

Moreira M.I.C. \& Borghi L. 1998. Deformações glaciogênicas na Formação Vila Maria (Siluriano, bacia do Paraná). In: Congresso Brasileiro de Geologia, 40., Belo Horizonte (MG), 1998. Anais... Belo Horizonte, SBG, p. 98.

Moreira M.I.C., Fernandes A.C.S. Borghi L. 1997. Skolithos "piperock" nas formações Alto Congresso Brasileiro de Paleontologia, 15, São Pedro, 1997. Boletim de Resumos... São Pedro, UNESP, p. 137.

Mussa D., Borghi L., Moreira M.I.C. 1997. Uma possível tafoflora pré-dcvoniana em Chapada dos Guimarães, borda Noroeste da bacia do Paraná. In: Congresso Brasileiro de Paleontologia, 15, São Pedro, 1997. Boletim de Resumos... São Pedro, UNESP, p. 29. some commcnts on gravclly mass-flow dcposits. In: Koster E. H. \& Steel R. J. (cds.) Sedimentology of graveis andconglomerates, Canadian Society of Petroleum Geologists, Memoir, 10.,p. 1-32.

N0ttvedt A. \& Kreisa R.D. 1987. Modcl for the combined-flow origin of hummocky cross-stratification. Geology, 15:357-361.

Oliveira M.A.M. \& Mühlmann H. 1967. Obscrvations on the gcology of Chapada dos Guimarães, Mato Grosso. In: Bigarclla J.J. (cd.) Problcms in Brazilian Devonian geology. Boletim Paranaense de Geociências, Curitiba. 21/22, p. 57-61.

Pereira E. 1992. Análise cstratioráfica do Paleozóico Médio da sub-bacia do Alto Garças, no sudoeste de Goiás. Bacia do Paraná, Brasil. Instituto de Geociências, Universidade Federal do Rio de Janeiro, Rio de Janeiro, Tese de Mestrado, 172p.

Selley R.C. 1985. Ancient sedimentary enviroments. 3.cd. Londres, Chapman and Hall, 317p.

van Wagoner J.C., Posamenticr H.W., Mitchum R.M., Vail P.R., Sarg J.F., Loutit T.S., Hardenbol J. 1988. An ovcrview of scquencc stratigraphy and kcy dcfinitions. In: Wilgus Ch.K., Hastings B.S., Kcndall Ch.G.St.C., Posamenticr H.W., Ross Ch.A., van Wagoner J.C., (cds.), Sca-lcvcl changcs: an intcgralcd approch. Sociely of Economic Paleontologists and Mincralogists, Special Publication, 42:39-45.

Walker R.G. \& Plint A.G. 1992. Wavc- and storm- dominated shallow marine systems. In: Walkcr R. G. \& James N. P. (cds.) Fácies models: responses to sea level change. Ontario, Gcological Association of Canada, p. 219-238. Tancrediopsis Bcushauscn, 1895 na bacia do Paraná e suas implicações. In: Congresso petroleum geology. Milan, Springcr. 582p. Garças c Furnas (Paleozóico, bacia do Paraná) no Estado de Mato Grosso, Brasil. In

Mutti E. 1992. Turbidite sandstones. Milão. Agip/Istituto di Geologia, Università di Parma. 275p.

Ncmec W. \& Steel R J. 1984. Alluvial and coastal conglomcratcs: their significam fcatures and 